\title{
Q41 Competitive mechanisms in sentence processing: Common and distinct production and reading comprehension networks linked to the prefrontal cortex
}

\author{
Q1 Gina F. Humphreys ${ }^{\mathrm{a}}$, Silvia P. Gennari ${ }^{\mathrm{b}, *}$
}

a Neuroscience and Aphasia Research Unit, School of Psychological Sciences, University of Manchester, Zochonis Building 3F, Brunswick St., Manchester M13 9PL, UK
b Department of Psychology, University of York, Heslington, York YO10 5DD, UK

\section{A R T I C L E I N F O}

\section{Article history:}

Accepted 21 August 2013

Available online $\mathrm{xxxx}$

\section{Keywords:}

Language production and comprehension

Competition

Interactive networks

Production planning

Language processing

LIFG

\begin{abstract}
A B S T R A C T
Despite much interest in language production and comprehension mechanisms, little is known about the 22 relationship between the two. Previous research suggests that linguistic knowledge is shared across these 23 tasks and that the left inferior frontal gyrus (LIFG) may be commonly recruited. However, it remains unclear 24 the extent to which production and comprehension share competition mechanisms. Here we investigate this 25 issue and specifically examine competition in determining the event roles in a sentence (agent or affected 26 participant). We used both behavioral and fMRI methods and compared the reading and production of high- 27 and low-competition sentences, specifically targeting LIFG. We found that activity in pars opercularis (PO), 28 independently identified by a competition-driven localizer, was modulated by competition in both tasks. 29 Psychophysiological interaction analyses seeded in PO revealed task-specific networks: In comprehension, 30 PO only interacted with the posterior temporal lobe, whereas in production, it interacted with a large 31 network including hippocampal, posterior temporal, medial frontal and subcortical structures. Production 32 and comprehension therefore recruit partially distinct functional networks but share competitive processes 33 within fronto-temporal regions. We argue that these common regions store long-term linguistic associa- 34 tions and compute their higher-order contingencies, but competition in production ignites a larger neural 35 network implementing planning, as required by task demands.
\end{abstract}

(C) 2013 Elsevier Inc. All rights reserved. 37
41

40
* Corresponding author at: Department of Psychology, University of York, York,
Y010 5DD, UK.

E-mail address: silvia.gennari@york.ac.uk (S.P. Gennari).
MacDonald, 2001). Gennari and MacDonald (2009), for example, 59 have shown that structural configurations that readers find difficult 60 are those that producers do not naturally produce, suggesting that 61 the mapping of lexical concepts into sentence structure is shared 62 across tasks. Similarly, a neuroimaging priming study comparing 63 sentence production and auditory comprehension has shown that 64 both tasks recruit a common fronto-temporal network including the 65 posterior temporal lobe and the left inferior frontal gyrus (henceforth 66 LIFG) (Menenti et al., 2011). However, the recruitment of common 67 brain regions does not necessarily imply that similar processes take 68 place in both production and comprehension - they could reflect 69 the recruitment of common semantic and grammatical knowledge, 70 common processes such as meaning access and sentence assembly 71 or a mixture of both. It remains unclear therefore whether and how 72 subcomponent processes in production and comprehension are 73 related, and in particular, whether competitive processes are shared 74 across the two tasks, despite the expected differences in input and 75 output networks.

To elucidate the extent to which production and comprehension 77 share cognitive and neural processes, rather than simply linguistic 78 and/or grammatical knowledge, here we chose to focus on processes 79 that arguably involve competition between alternative representations. 80 
Such competition may occur in comprehension when multiple alternative interpretations are activated and resolution between them takes place. In studies of lexical ambiguity, for example, equally frequent meanings of an ambiguous word like bowl are initially activated, and competition resolution is required to arrive at the intended meaning, often with the help of contextual cues (Duffy et al., 1988; Gennari et al., 2007; Rayner and Duffy, 1986; Rayner et al., 1983; Rodd et al., 2005, 2010; Seidenberg et al., 1982; Swinney, 1979; Tanenhaus et al., 1979). At the sentence level, similar semantic competition processes take place when alternative conflicting interpretations are activated as the sentence unfolds (Novick et al., 2005; Rodd et al., 2010; Tanenhaus and Trueswell, 1995). Competition resolution may also occur in production when alternative utterances, e.g., alternative sentence structures or words, are associated with the intended meaning (Gennari et al., 2012), or in the case of cued production, when alternative utterances are strongly associated with the cue (Barch et al., 2000; Spalek and Thompson-Schill, 2008). For example, in elicitation studies in which participants must produce a verb/action in response to a cuing noun, strong associations like scissors-cut are easier to utter than weaker associations, e.g., wheelturn, because these weaker associations compete with other available alternatives (Barch et al., 2000; Thompson-Schill et al., 1997). Cue-based production, which is used in the present study, is thus similar to ambiguity resolution in comprehension in that the appropriate response to the cue is essentially ambiguous, as more than one alternative utterance is activated (see for example numerous picture-word interference studies (Costa et al., 2005)). Therefore both production and comprehension can involve competition between available alternative interpretations or utterances. Finding evidence of brain regions and behaviors that are similarly sensitive to conflicting demands in both production and comprehension would suggest that processes of a competitive nature are shared across tasks.

Although some neurocognitive studies suggest that competition occurs in both production and comprehension, particularly within LIFG, psycholinguistic approaches have typically argued that these tasks involve distinct component processes that act upon a shared linguistic knowledge base (Bock and Levelt, 1994; MacDonald et al., 1994). Indeed, production requires word retrieval and planning of a sentence structure, whereas comprehension involves word recognition and the understanding of syntactic-semantic relations between words. These processes have long been argued to give rise to marked asymmetries between these tasks. Sentence production for example often involves false starts, disfluencies and errors, which are thought to arise from production planning and articulation processes not shared with comprehension (Bock and Levelt, 1994; Garrett, 1980; Levelt et al., 1999). Furthermore, with specific reference to competition, sentence comprehension involves activating multiple alternative interpretations of polysemous stimuli (MacDonald et al, 1994), but in production polysemy is sometimes unnoticed by speakers, who have a single intended meaning in mind (Ferreira et al., 2005). This suggests the possibility that generally assumed competition mechanisms in fact differ across production and comprehension tasks. Differences in the types of tasks faced by speakers and comprehenders might lead to differences in the underlying processing systems. These observations are consistent with many production studies recruiting partially distinct neural networks from those typically found in comprehension studies, including supplementary motor regions, the cingulate cortex, and subcortical structures that are associated with motor responses and decisions (Barch et al., 2000; Sörös et al., 2006; Tremblay and Small, 2011; Whitney et al., 2008). Nonetheless, patients with pre-frontal or LIFG lesions show both production and comprehension impairments in cognitively demanding tasks (Jefferies and Lambon Ralph, 2006; Novick et al., 2009) and both readers and speakers show similar brain correlates of assumed competition processes in LIFG and nearby regions, albeit across different studies (Bedny et al., 2008b; de Zubicaray et al., 147 2001; Heim et al., 2009; Indefrey, 2011; Spalek and Thompson- 148 Schill, 2008; Tyler and Marslen-Wilson, 2008). This thus indicates 149 that both tasks may recruit the LIFG under competition demands 150 (Thompson-Schill et al., 2005).

Together these findings suggest that the LIFG may play a role in 152 both production and comprehension when resolving competition, 153 but that there may also be differences in the networks implementing 154 competition in each task and cooperating with LIFG. To evaluate this 155 possibility, we used behavioral measures (Experiment 1) and func- 156 tional magnetic resonance imaging (Experiment 2) to examine the 157 networks interacting with LIFG in the production and reading compre- 158 hension of sentences taken to vary in competition demands (high- vs. 159 low-competition). We used reading rather than auditory compre- 160 hension because reading is more appropriate for a noisy environ- 161 ment like the MRI scanner, this task circumvents debated design 162 decisions such as appropriate baseline (Adank, 2012) and because 163 many studies comparing reading and listening with non-competitive 164 stimuli report little or no differences in supramodal language regions 165 such as LIFG and the posterior middle temporal gyrus that are likely 166 to be engaged in processing the present stimuli (Adank, 2012; Buchweitz 167 et al., 2009; Jobard et al., 2007; Lindenberg and Scheef, 2007; Michael 168 et al., 2001). Example stimuli can be found in Table 1.

In the reading comprehension task, we chose subordinate clauses 170 such as the director that the movie impressed... and the movie that 171 the director watched... for our stimuli because these structures have 172 been amply demonstrated to vary in difficulty in previous studies 173 (Mak et al., 2002, 2006; Traxler et al., 2002). Specifically, high- 174 competition clauses take longer to read and elicit more activity in 175 LIFG than low-competition ones (Caplan et al., 2008; Chen et al., 176 2006; Gennari and MacDonald, 2008). This difficulty plausibly arises 177 because conflicting lexical and structural cues lead to incorrect pre- 178 dictions regarding the event roles in the sentence: animate and inan- 179 imate nouns like director and movie cue an agent and an affected- 180 participant event role respectively, however structural markers and the 181 subordinate verb cue the opposite roles. The first high-competition struc- 182 ture in Table 1, for example, is incompatible with an interpretation in 183 which the director writes or watches the movie - the situations 184 most typically associated with these nouns at the point at which 185 the subordinate verb impressed is encountered. At this point, readers 186 anticipate potential relations between director and movie, e.g., the 187 director writing or watching the movie, or the movie being about 188 the director, none of which is the interpretation implied by the 189 verb impress in the subordinate clause, generating conflict between 190 currently available and incoming interpretations. As in cases of am- 191 biguity, alternative interpretations are entertained at this point, as 192 the reader must inhibit the initially constructed interpretation in 193 favor of the one cued by incoming words. In the low-competition 194 condition, in contrast, the nouns and the structure lead to the ulti- 195 mately correct interpretation in terms of event roles (the movie being 196 watched by the director). These interpretation preferences have been 197

Table 1

Example stimuli for the production and the comprehension task.

\begin{tabular}{|c|c|c|}
\hline Task & Condition & Example stimulus items \\
\hline \multirow[t]{2}{*}{ Comprehension } & High-competition & $\begin{array}{l}\text { 1. The director that the movie impressed } \\
\text { had received a prize } \\
2 \text {. The banker that the loan worried was } \\
\text { short of money }\end{array}$ \\
\hline & Low-competition & $\begin{array}{l}\text { 1. The movie that the director watched had } \\
\text { received a prize } \\
2 \text {. The loan that the banker refused was a lot } \\
\text { of money }\end{array}$ \\
\hline \multirow[t]{2}{*}{ Completion } & High-competition & $\begin{array}{l}\text { 1. The director that the movie ... } \\
\text { 2. The banker that the loan .... }\end{array}$ \\
\hline & Low-competition & $\begin{array}{l}\text { 1. The movie that the director ... } \\
2 \text {. The loan that the banker .... }\end{array}$ \\
\hline
\end{tabular}


demonstrated by eliciting readers' interpretations at each point in the subordinate clause. Critically, the number of alternative interpretations available at the point in which the subordinate verb is encountered predicts reading times at subsequent word positions, thus supporting competition claims (Gennari and MacDonald, 2008).

In the production task, we used a cue-based paradigm in which participants completed sentence fragments from the comprehension stimuli into full sentences (Table 1). This production task showed parallel competition results to those obtained in comprehension. Specifically, here we found that high-competition fragments take longer to complete than low-competition fragments and that the number of alternative continuations or plans produced for these fragments (by different speakers) correlates with production initiation times. Taken together, the present and previous findings with our stimuli strongly suggest the presence of competition between alternatives in interpreting the sentences or providing a continuation for prompt fragments (production). Otherwise, it would be unexplained why activating more alternatives leads to longer processing times, and why the number of alternatives available correlates with performance in both tasks, given that only one of the alternatives is eventually produced or understood. Indeed, ambiguity resolution processes and cuebased multiple-alternative productions have long been conceived as competitive processes in psycholinguistics and cognitive neuroscience, both at the lexical and the sentential level (Costa et al., 2005; de Zubicaray et al., 2001; MacDonald et al., 1994; Novick et al., 2005: Simpson, 1994; Spalek and Thompson-Schill, 2008), given that such cases appear distinctive from other difficult processes, for example, the difficulty experienced in retrieving the meaning of a low frequency word. Our behavioral production and comprehension tasks therefore provide appropriate support to examine the brain correlates of competition mechanisms in each task.

In Experiment 2 using fMRI, we conducted the same production and reading comprehension tasks as above, except that production was covert to minimize movement. We also conducted a localizer Stroop task, which was primarily used to identify a relevant region of interest associated with competition processes within LIFG - a functionally and anatomically heterogeneous region (Amunts et al., 2010; Chein et al., 2002; Dapretto and Bookheimer, 1999; Fedorenko et al., 2012; Petrides, 2005). We focused on LIFG rather than other regions typically activated by the Stroop task (Milham et al., 2001) because, as suggested above, portions of the LIFG, unlike other regions of the Stroop network, are very likely candidates to be recruited by both production and comprehension, as they have already been argued to play a regulatory, control or unifying role in many models of language processing (Hagoort, 2005; Indefrey, 2011; Tyler and Marslen-Wilson, 2008). The Stroop task was designed in such a way that allowed the identification of voxels sensitive to the representational conflict in this task, rather than the response conflict (Hindy et al., 2012; January et al., 2009). Within the LIFG, we identified these voxels for each individual participant and evaluated the activity elicited by the conditions in each production and comprehension. Individualbased analyses guarantee a high degree of anatomical specificity that is not influenced by normalization procedures or anatomical differences across participants (Fedorenko et al., 2010; Glezer and Riesenhuber, 2013; Juch et al., 2005; Nieto-Castañón and Fedorenko, 2012; Saxe et al., 2006; Swallow et al., 2003). Additionally, we conducted psychophysiological interaction analyses using the identified LIFG cluster as seed region to determine the networks cooperating with it as a function of competition condition.

Based on the view outlined above, if the LIFG is involved in resolving competition in both production and comprehension, we predicted that the levels of competition in both production and comprehension should modulate activity within a region of the LIFG also sensitive to semantic competition in the Stroop task (localizer). Critically, if each task implements competition processes differently and contains specific component processes, as suggested by psycholinguistics research, distinct task-specific neural networks should interact with the identi- 264 fied portion of LIFG as a function of competition resolution demands, 265 i.e., the competition networks revealed by the psychophysiological in- 266 teraction analysis should differ according to task. These predictions 267 assume that our stimuli indeed capture competitive processes, as 268 suggested by our behavioral results and previous literature, and 269 that the Stroop task, and particularly, the specific contrast utilized, 270 also captures some aspects of the conflict resolution between repre- 271 sentations within LIFG (Hindy et al., 2012; January et al., 2009; 272 Milham et al., 2001).

Methods

Experiment 1: behavioral study

Participants

39 native English speaking students at the University of York partic- Q6 ipated in the experiment and received course credit for their participa- 278 tion $($ mean $=22.5$ years, $\mathrm{SD}=3.08$, range $=18-32,22$ females ).

\section{Materials}

Items in the comprehension task had two versions varying in the 281 configuration of the noun animacy and the subordinate verb within 282 the subordinate clause, yielding a high-competition and a low- 283 competition version (see Table 1). As indicated above, the syntactic 284 configuration of the animate and inanimate nouns in the high- 285 competition condition causes competition between alternative in- 286 terpretations as the sentence unfolds: the event roles strongly asso- 287 ciated with the animacy of the nouns (animate and inanimate nouns 288 are typically agents and affected-participants respectively) must be 289 inhibited in favor of the infrequent event role interpretation provid- 290 ed by the subordinate verb (Gennari and MacDonald, 2008; Mak 291 et al., 2002; Traxler et al., 2002, 2005). Previous work has carefully 292 documented the presence of competition between alternative inter- 293 pretations involved during reading and is consistent with similar 294 views proposed in the cognitive neuroscience literature (Novick 295 et al., 2005).

There were 84 stimulus sentences in total. 42 experimental items 297 with subordinate clauses such as those in Table 1 were used, along 298 with 42 filler sentences. Participants were asked to read these sentences 299 and fully understand their meaning (see below for details). The nouns 300 and the verbs of the stimulus sentences were matched for length and 301 frequency across conditions (see Table 2). The majority of the filler 302 sentences (80\%) were subject-verb-object main clause structures. 303 The remaining filler sentences included some form of subordinate 304 or conjoined structure.

Items in the production task were similar to those in the compre- 306 hension task but only included the initial fragment of the sentences 307 (Table 1). The task instructions required the participant to complete 308 the fragment into a full sentence (see below for details). This thus re- 309 quired speakers to assign event roles to the nouns of the fragment 310 and to select an appropriate verb phrase to continue it that matched 311 the meaning of the nouns. Our previous and present results suggest that 312 more alternative continuations are available in the high-competition 313 fragments than the low-competition ones (Gennari and MacDonald, 314

Table 2

The mean log word frequencies and length for the nouns and verbs from the high competition and low-competition conditions.

\begin{tabular}{lllllr}
\cline { 1 - 2 } Condition & Example & Log word frequency & Length & t2.4 \\
\cline { 1 - 3 } High-competition noun & Director & 4.18 & 6.88 & t2.5 \\
Low-competition noun & Movie & 4.27 & 6.02 & t2.6 \\
High-competition verb & Impressed & 4.05 & 7.64 & t2.7 \\
Low-competition verb & Watched & 4.08 & 7.57 & t2.8 \\
\cline { 1 - 3 }
\end{tabular}


2008, henceforth G\&M), and thereby, more competing utterance plans, within the semantic and syntactic constraints of the fragment.

\section{Task design}

Two tasks, sentence comprehension and sentence completion, were conducted within the same experimental session arranged in two separate blocks with separate instructions. For each task, the items were split across two lists with each list containing 42 experimental items (21 high-competition and 21 low-competition sentences) and 42 filler sentences. Each participant saw only one list for each task. The lists were constructed in such a way that the high-competition and low-competition versions of the same item would be on a separate list for a given task (Latin-square design), but the two versions would be seen once in the production task and once in the comprehension task. The order of the items was randomized and randomly intermixed with filler sentences. The order of the production and the comprehension task was counterbalanced across participants.

\section{Procedure}

In the comprehension block, participants were told to read the words one at a time in a self-paced moving-window paradigm (G\&M) and fully understand the meaning of the sentence. After each sentence, a comprehension question was asked, requiring a YES/NO answer (e.g., did the movie impress the director?). $53 \%$ of these questions referred to the content of the subordinate clause. Reading times and comprehension accuracy were recorded. In the production block, participants read the fragments one word at a time as in comprehension, and were instructed to fully understand their meanings before initiating their completions out loud. We recorded their spoken responses to compute response accuracy, and the time it took them to initiate or plan their utterances, as measured from the offset of the last word processed in the initial fragment. We also checked that participants read each word of the fragment carefully, as instructed, rather than waiting until the end of the phrase to comprehend the fragment, by comparing the reading times of the fragments across tasks. Reading times for the fragments in the production task were indeed much slower than in the comprehension task (for contrasts at all word positions, $\mathrm{p}<.001$ ). In particular, the reading times of the last word of the fragment (the last noun) was on average $2205 \mathrm{~ms}$ longer in the completion task than in reading comprehension, thus suggesting that participants read carefully in anticipation of, or in preparation for, their upcoming completion task.

\section{Data coding and analysis}

To analyze the production responses, we identified completion errors by simple inspection of the transcribed utterances. Continuations that did not make sense were considered errors. For example, for a fragment such as the scientist that the book, the completion had written was considered an error, as books typically do not write scientists. Two independent researchers coded the data and they agreed on more than $95 \%$ of the cases coded. Cases of disagreement were discussed among researchers and a final coding was jointly decided. Additionally, we computed a measure indexing competition: the proportion of different verbs produced across speakers for each item in the completion task (out of the total number of completions for that item). This measure represents how many different verb continuations there are in general for each item and thus, reflects the number of alternative continuations potentially entertained during planning, even though a given participant would have ultimately produced only one of them. Two continuations were considered to contain the same verb if the same lexical root of the verb was used, independently of tense or auxiliaries (e.g., hit, had hit). For the example in Table 1, the continuations were displeased, pleased, impressed, upset, used, was about, watched, was directed by, and had watched, which amounted to 8 different completions ( 0.88 proportion). In our analyses, we used this measure to predict planning difficulty.
Data analyses of processing times (planning and reading times) 378 were all carried on correct responses only (correct production 379 trials and sentences for which participants answered the compre- 380 hension question correctly). For the analysis of reading times, 381 residual reading times were used as the dependent measure, as 382 standard in psycholinguistics, although raw reading times display the 383 same effects, as shown in Fig. 1. Residuals are calculated from regressing 384 out word length from raw reading times (G\&M). For the analysis of pro- 385 duction planning times, we used log transformed times to approximate 386 normally distributed data points, although analyses of raw planning 387 times yield the same results. Responses that deviated by more than 388 3.5 SDs from the mean initiation times were removed from the analysis. 389

\section{Results}

Comprehension task

Results indicated that as expected, high- vs. low-competition 392 sentences differ in comprehension difficulty: participants were less ac- 393 curate and reading times were slower for high-competition sentences 394 than low-competition sentences, and there was no interaction between 395 task order and competition conditions. Fig. 1 plots the reading times for 396 each word position as a function of condition. The overall mean accuracy 397 across participants for the comprehension questions was 89\% (SD 2.71). 398 Response accuracy for the high-competition items was significantly 399 lower than the low-competition items suggesting increased compre- 400 hension difficulty in the high competition case (by-item analysis: 401 high-competition $\mathrm{M}=84 \%, \mathrm{SD}=16.15$; low-competition $\mathrm{M}=94 \%, 402$ $\mathrm{SD}=11.22 ; \mathrm{t}(39)=-3.23, \mathrm{p}=.003$; by-participant analysis: high- 403 competition $\mathrm{M}=84.33 \%$, $\mathrm{SD}=10.41$; low-competition $\mathrm{M}=93.86 \%, 404$ $\mathrm{SD}=6.60 ; \mathrm{t}(38)=5-.01, \mathrm{p}<.0001)$. A repeated measures ANOVA 405 with residual reading time as the dependent variable and condition 406 (high- vs. low-competition) and word-position (subordinate noun, 407 e.g. movie, subordinate verb, e.g. pleased, and the main verb region, e.g. 408 had received $a$ ) as factors revealed a main effect of condition (by-item 409 analysis: $\mathrm{F}(1,39)=7.55, \mathrm{p}=.009, \eta \mathrm{p}^{2}=.16$; by-participant analysis: 410 $\left.\mathrm{F}(1,38)=10.34, \mathrm{p}=.003, \eta \mathrm{p}^{2}=.21\right)$. No main effect of position was 411 found and there was no condition by position interaction. Planned com- 412 parisons showed significantly slower residual reading times for the 413 high-competition vs. low-competition condition at the subordinate 414 verb (by-item analysis: $\mathrm{t}(39)=2.31, \mathrm{p}=.026$; by-participant analysis: 415 $\mathrm{t}(38)=2.54, \mathrm{p}=.015$ ), and also at the main verb region (by-item 416 analysis: $\mathrm{t}(39)=2.80, \mathrm{p}=.008$; by-participant analysis: $\mathrm{t}(38)=417$ $3.85, \mathrm{p}<.0001)$. Finally, a mixed ANOVA with residual reading times 418 as dependent variable, competition conditions as repeated factors and 419 task order as between subjects factor revealed no interaction of compe- 420 tition with task order at any of the critical verb positions. Taken to- 421 gether, these results replicate previous findings in the literature 422 (Gennari and MacDonald, 2008; Mak et al., 2002; Traxler et al., 423 2002) confirming the suitability of our stimuli, and suggest that as 424 the sentence proceeds, readers encountered more difficulty at the 425 subordinate verb position, which indicates who is doing what in 426 the subordinate structure. This difficulty continues into the main 427 verb phrase of the sentence.

\section{Production task}

Results indicated that high- vs. low-competition sentences dif- 430 fer in production difficulty: response accuracy was lower and initi- 431 ation times longer for the high-competition condition than the 432 low-competition condition and there was no interaction between 433 competition conditions and task order. Across participants and 434 items, there was a significantly lower proportion of correct responses 435 for the high-competition condition than the low-competition condition 436 (by-item analysis: high-competition $\mathrm{M}=.81, \mathrm{SD}=.16$; low- 437 competition $\mathrm{M}=.97, \mathrm{SD}=.06 ; \mathrm{t}(39)=-6.47, \mathrm{p}<.001 ;$ by- 438 participant analysis: high-competition $\mathrm{M}=.81$, $\mathrm{SD}=.21$; low- 439 competition $\mathrm{M}=.97, \quad \mathrm{SD}=.09 ; \mathrm{t}(36)=-5.92, \quad \mathrm{p}<.001) .440$ 


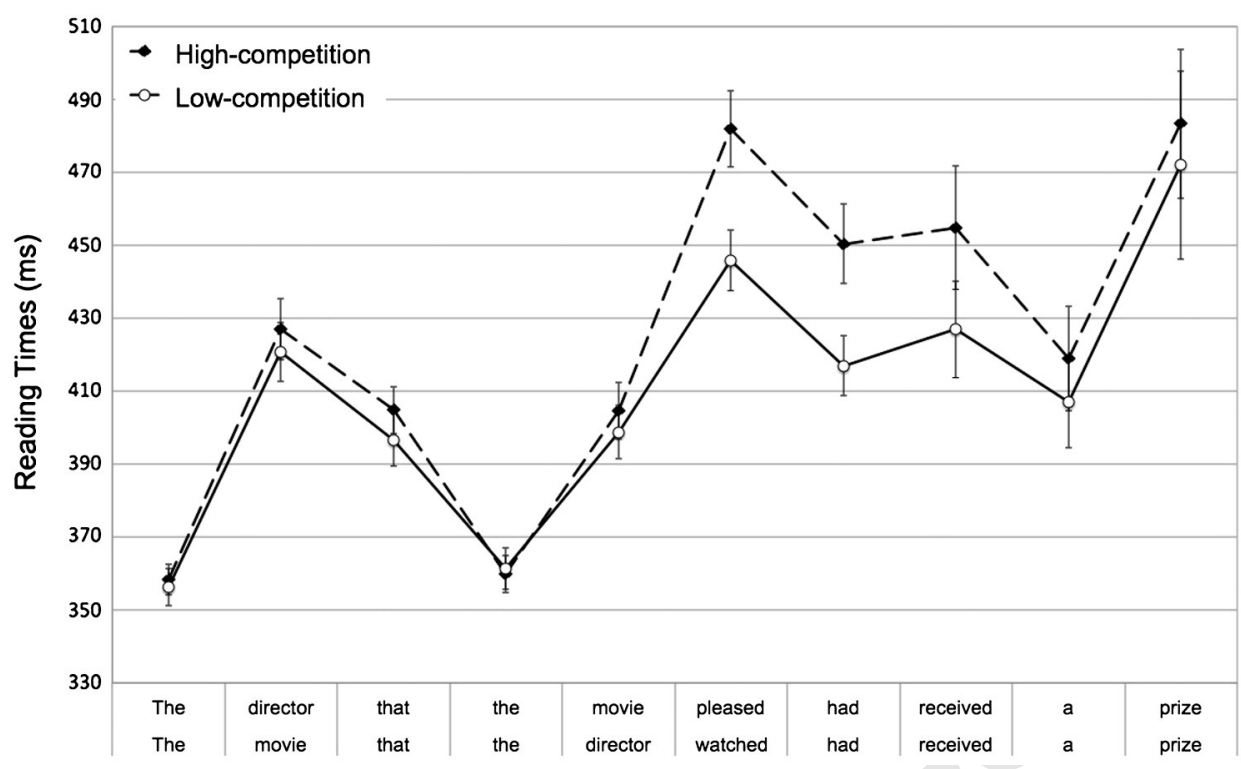

Fig. 1. Reading times as a function of condition and word position in Experiment 1. Error bars indicate standard error.

Interestingly, the majority of errors in these responses $(60.4 \%)$ were event role errors, i.e., errors in which the produced verb implies the wrong sentential roles for the nouns of the fragment, as in The director that the movie... "watched was good". These errors clearly suggest that participants found it difficult to inhibit prepotent verb responses associated with the nouns, e.g. the verb watch is strongly associated with director and movie. Moreover, log transformed planning times were longer for the high-competition compared to lowcompetition items (item analysis: $\mathrm{t}(39)=5.13, \mathrm{p}<.001$; subject analysis: $\mathrm{t}(38)=6.51, \mathrm{p}<.001)$. Raw planning times are shown in Fig. 2. These results remained significant after controlling for utterance length in a hierarchical regression analyses across items. Length alone explained $13 \%$ of the variance in initiation times, a significant predictor $(\mathrm{F}(1,78)=11.73, \mathrm{p}<.001)$, but adding condition (highcompetition vs. low-competition) into the model significantly increased the variance explained to $22 \%$ (F change $(1,77)=8.85$, $\mathrm{p}<.005)$. This confirms that high-competition fragments are more difficult to complete, irrespective of utterance length. Finally, a mixed ANOVA with planning time as the dependent variable, competition conditions as repeated factors, and task order as between subjects factor revealed no interaction of competition with task order $(\mathrm{F}(1,37)=1.37, \mathrm{p}=$ n.s. $)$.

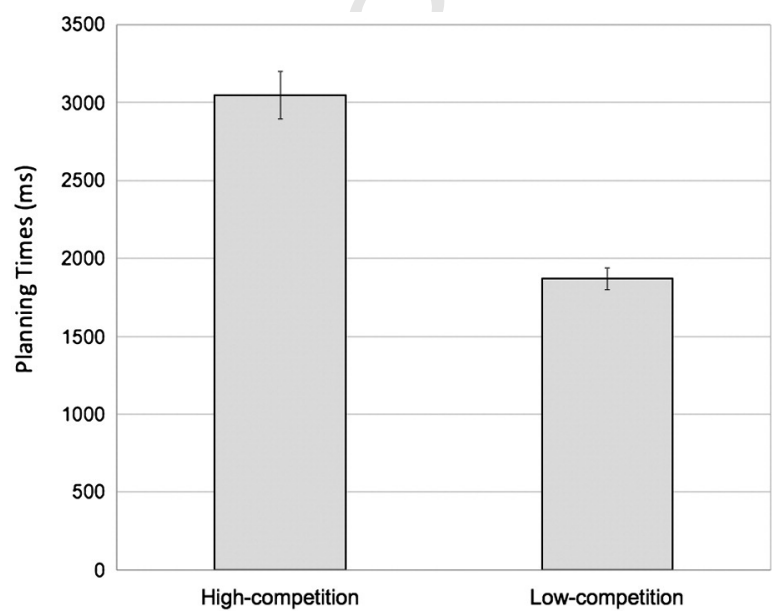

Fig. 2. Production planning times as a function of condition in Experiment 1. Error bars indicate standard error.
Correlation

To shed light on whether the differences in difficulty that we 464 have revealed in production planning suggest underlying compet- 465 itive processes, as previously reported for the comprehension of 466 our items, we correlated the number of alternative continuations 467 with initiation times. We used the proportion of different verbs 468 produced across speakers for each item in the completion task (see Data 469 coding and analyses) and regressed it onto the average planning times 470 for each item, including both high- and low-competition cases. We there- 471 fore expected that if competition between alternative continuations 472 took place during production planning, this correlation should be 473 significant. Indeed, the proportion of alternative verbs accounted 474 for $40 \%$ of variance in planning times $(\mathrm{p}<.0001)$. This result paral- 475 lels previously reported results in the comprehension of these struc- 476 tures in that the number of interpretations entertained up to the 477 relative clause verb predicts reading difficulty at subsequent word 478 positions (G\&M).

Taken together, these results suggest that both production and 480 comprehension show processing difficulty in the high-competition 481 condition and both tasks are sensitive to the number of alternative 482 interpretations or plans entertained, thus strongly suggesting com- 483 petitive processes.

Experiment 2 - fMRI study

Participants

486

17 right-handed native English speaking students at the University Q7 of York, who did not take part in Experiment 1, participated in this 488 study. All participants had no history of psychiatric illness or neuro- 489 logical damage (10 males, 7 females, mean age $=23.2$ years, $S D=490$ 3.72 , range $=19-33$ years $)$.

Materials

The same 42 items and fragments used in Experiment 1 (see Table 1), 493 were used in this experiment (84 experimental items in total).

Task design

Three fMRI scans were conducted: comprehension task, production 496 task, and a color Stroop task. The Stroop task was used as a localizer to 497 identify a region of interest involved in semantic competition resolution 498 within LIFG. The order of the production and comprehension scans was 499 counterbalanced across participants, as in Experiment 1, and the Stroop 500 
task was always completed last. The production and comprehension scans were presented in an event related design. The most efficient ordering of events was determined using Optseq (http://www.freesurfer. net/optseq). Null time was intermixed between trials and randomly varied between 0 and $18 \mathrm{~s}$, with an averaged inter-trial time of $4.67 \mathrm{~s}$ (Josephs and Henson, 1999). Every event type followed each other with equal probability (e.g., for three event types, every type followed every other across the experiment $33 \%$ of the time). Due to practical time constraints, we did not include fillers in this experiment.

Reading comprehension task. In each event a sentence was visually presented (white font on a black background) split into two consecutive halves of $3 \mathrm{~s}$ each. The first half contained the subordinate clause (e.g. The movie that the director watched) and the second half contained the remaining of the sentence. Whole sentence presentation has been successfully used with relative clause stimuli both in behavioral studies (Traxler et al., 2002, 2005) and fMRI studies (Chen et al., 2006; Caplan et al., 2007). This is a more appropriate paradigm to use with fMRI, compared to self-paced reading, given that activity to individual words in the sentence could not be estimated in any case due to the sluggishness of the hemodynamic response. Furthermore, we did not follow the selfpaced method of Exp. 1 because we did not want to contaminate reading comprehension activity with motor activity involved in button presses, which could possibly make comprehension more similar to production. In order to ensure that the participants were processing the meaning of the sentences, 16 catch-trials were randomly intermixed with experimental trials. Catch trials took the form of YES/NO comprehension questions as in Experiment 1. The participants were given $4 \mathrm{~s}$ in which to answer the question. Between trials a series of "+"s was presented which was the same length as the average sentence length. This acted as a visual baseline. In total the scan lasted $906 \mathrm{~s}$.

For each subject, the high-competition and low-competition version of an item were assigned to different halves of the experiment so that if one version appeared in the first half of the experiment, the remaining version appeared in the second half. The two halves of the experiments were counterbalanced across subjects so that each subject saw the two versions of an item in a different order. Across all items, half were presented first in the high-competition condition and half in the low-competition condition, so that in each half of the comprehension task, there were equal numbers of sentences from each condition. This careful counterbalancing eliminates potential influences of item order on both group statistics (each participant saw a different order) and the average activity for a condition within a participant (across items, each half was presented in a different order). This design followed Chen et al. (2006) and Caplan et al. (2008) who have found positive results using a similar paradigm.

Production task. Each trial presented a sentence fragment for $2 \mathrm{~s}$ after which the symbols "???" appeared for 6 s. Participants were instructed to covertly complete the sentence fully and meaningfully when they saw these symbols and to press a button when they were finished. Note that this task was not aimed at removing articulatory aspects of production, since overt and covert production sometimes similarly activate common regions, e.g., supplementary motor cortex and insula, but not LIFG (Huang et al., 2001). On the contrary, whatever motor planning and articulatory processes take place in production ought to be reflected in the production network, but not in comprehension. To act as a reading baseline, 84 read-only items were intermixed with the production items. Here, the participant was instructed to simply read the fragment for meaning and press a button when they were finished reading. These items and trials were identical to the completion fragments except that they were presented in red font and followed by "XXX". After practice, the font color thus clearly indicated from the beginning of the trial whether participants would complete or read the stimulus fragments. By contrasting the activity from the completion trials and the readonly trials, we aimed to remove the reading component of the trial, revealing only production-related activity. Note that regions found 565 to be active only in the completion task, as compared to the compre- 566 hension task above, which constitute the majority of our results, can- 567 not be attributed to any influence of the reading component of the 568 completion task. If for example, the reading component of the com- 569 pletion task was not successfully removed (via the contrast between 570 the completion trials and the read-only trials), we would expect the 571 production results to be similar to the comprehension results from 572 the main comprehension task above, which was clearly not the case. 573

The production scan was divided into two runs, one lasting 842 s 574 and the other lasting $830 \mathrm{~s}$. As in the comprehension task, the order 575 for the runs was counterbalanced across participants. The runs were 576 structured such that if a high-competition production item was 577 presented in run 1 , then the read-only version of this item would 578 be presented in run 2 and vice versa. Also, the items from the high- 579 and low-conditions were ordered such that if the high-competition 580 version of an item was presented in the first run, then low- 581 competition version would not be presented until the second run 582 and vice versa. Thus the order in which the conditions occurred 583 was also counterbalanced across runs. Across all items, half were 584 presented first in the high-competition condition and half in the 585 low-competition condition, so that in each half of the comprehen- 586 sion task, there were equal numbers of sentences from each condi- 587 tion. Additionally, the order of event types was determined by 588 Optseq and was such that each event type followed each other equal- 589 ly often. This careful counterbalancing of conditions across runs and 590 participants makes it unlikely that content repetition between some 591 items (e.g., read-only and completion trials) would have an influence 592 on the group results. Similarly, any potential influence of task changes 593 in the production session (completion vs. reading-only) would not un- 594 duly influence any specific condition, thus allowing safe comparisons 595 between high- and low-competition trials.

Stroop task (localizer). This task was taken from previous studies 597 (Milham et al., 2001), and has successfully been used in similar 598 language studies in the literature (Hindy et al., 2012; January et al., 599 2009). The responses were restricted to three font colors - yellow, 600 green and blue. The task was to indicate the font color by pressing a but- 601 ton on a button box, whilst ignoring the word meaning. There were 602 three conditions: incongruent-eligible, incongruent-ineligible, and neu- 603 tral. In the incongruent-eligible trials, the word and ink color were in- 604 congruent and the word denoted a color that was a potential response 605 (yellow, green, or blue). In the incongruent-ineligible trials, the word 606 denoted a color that was not a potential response (orange, brown, or 607 red). The distinction between eligible and ineligible trials is that eligible 608 trials will involve both conflict at the motor response level (since the 609 word indicates a possible response), as well as conflict at the repre- 610 sentational level (since both the word and the ink involve color rep- 611 resentations). However, ineligible trials will only involve conflict at 612 the representational level (January et al., 2009). Neutral trials consisted 613 of non-color words that were length and frequency matched to the 614 color items (e.g. plenty, horse, deal). The trial structure and design 615 were identical to that in January et al. (2009) and Hindy et al. (2012). 616

Acquisition parameters. Imaging was carried out using a 3 T Signa 617 Excite MRI scanner at the York Neuroimaging Centre (YNiC). High- 618 resolution whole brain T1-weighted structural images were obtained 619 for all participants $(1 \mathrm{~mm} \times 1 \mathrm{~mm} \times 1 \mathrm{~mm})$. Functional images were 620 obtained using a gradient-echo EPI sequence with 38 contiguous axial 621 slices per volume $\left(\mathrm{TR}=2000 \mathrm{~ms}\right.$, $\mathrm{TE}=20 \mathrm{~ms}$, flip angle $90^{\circ}$, matrix 622 $64 \times 64$, FOV $24 \mathrm{~cm}$, slice thickness = $3.5 \mathrm{~mm}$ ). A T1-weighted FLAIR 623 image was also obtained to aid co-registration.

Data analysis. Data analyses were carried out using FSL tools 625 (the software library of the Oxford Centre for Functional MRI of the 626 Brain (FMRIB); www.fmrib.ox.ac.uk/fsl). First- and higher-level analy- 627 ses were carried out using FEAT (FMRI Expert Analysis Tool). The two 628 production runs were combined by concatenating their demeaned 629 
data. Pre-processing of the data included motion correction (Jenkinson et al., 2002), slice-timing correction, brain extraction, spatial smoothing using a Gaussian kernel of full-width-half-maximum (FWHM) $8 \mathrm{~mm}$, and high-pass temporal filtering (Gaussian-weighted least-squares straight line fitting, sigma $=25.0 \mathrm{~s}$ ). Time series analyses were conducted using FILM (FMRIB's Improved Linear Model) with local autocorrelation correction (Woolrich et al., 2001).

The data from each task were modeled separately with event-based explanatory variables corresponding to the condition and trial structure, which were convolved with a hemodynamic response function (gamma function). For all tasks, hemodynamic response functions (HRFs) were aligned to the beginning of the event and lasted for the duration of the event except for the production trials, which were modeled as lasting $4.5 \mathrm{~s}$. This aimed to capture the reading portion of the trial $(2 \mathrm{~s})$ plus the planning and initial encoding of the utterance, rather than the articulation. This timing was determined using data from Experiment 1 (the mean initiation times were around $2.5 \mathrm{~s}$, see Fig. 2). Thus, if there were length differences across participants' utterances, there were not taken into account in the modeling, which only captured the initial planning.

Several contrasts were computed for each data set. For the comprehension task, we contrasted all the sentences relative to the visual baseline (language-baseline), and each condition separately relative to baseline (high-competition-baseline; low-competitionbaseline). We performed similar contrasts on the production data but this time contrasting the experimental trials with the read-only control trials. There were three production contrasts: all production $>$ control, high-competition production $>$ control, low-competition production $>$ control. Higher-level group analyses comparing activity across conditions or across tasks were conducted by entering participants' lowerlevel contrast parameter estimates into high-level statistics (cluster corrected, $\mathrm{z}>2.3, \mathrm{p}=.05$ ). In turn, the Stroop data was modeled with covariates for each condition. The main contrast of interest was the representational competition contrast in which incongruent ineligible items were contrasted with neutral items.

Region of interest analysis. The Stroop data was used to identify a portion of LIFG most strongly responding to semantic conflict in each participant, using the contrast between ineligible vs. neutral trials to capture the representational conflict (see description of the Stroop task above). This portion, which turned out to be within the pars opercularis (BA44) was significantly (and more strongly) active in a group level analysis (cluster corrected $\mathrm{z}>3, \mathrm{p}=.05$ ), and was also consistently activated in all participants, as revealed by individual results. This region is considered to play a central role in competition resolution in language processing and other cognitive tasks (Miller and Cohen, 2001; Thompson-Schill et al., 2005). For our region of interest analysis, we identified this region in each individual brain by visual inspection of the high-resolution contrast images for the ineligible vs. neutral Stroop trials. We initially drew a mask on the active cluster falling within the pars opercularis, which was delimited by the inferior precentral sulcus posteriorly, the inferior frontal sulcus dorsally, the lateral fissure ventrally and the vertical ramus of the lateral fissure anteriorly. From these clusters, we then extracted the 35 most active voxels by thresholding the clusters at the appropriate level for each participant and transformed each resulting ROI into each individual's functional space. Within each ROI, we computed average measures of language activity for each participant. For the comprehension results, we extracted the mean contrast parameter estimates for the high-competition vs. baseline and low-competition vs. baseline contrasts. For the production results, we extracted the corresponding parameter estimates, i.e., highcompetition vs. read-only control and low-competition vs. the readonly controls. These mean contrast parameter estimates were then converted into percent signal change and used as dependent variables in random-effect group analyses reported for each task to test whether there was an effect of condition across participants.
Psychophysiological interaction analyses. In order to examine the net- 694 works that are engaged during competition resolution in the production 695 and the comprehension tasks, we conducted functional connectivity 696 analyses using the psychophysiological interaction method. Specifi- 697 cally, we aimed to determine whether the functional coupling be- 698 tween the pars opercularis and other brain regions interacts with 699 task demands (levels of competition) in different ways for produc- 700 tion and comprehension. This allows an examination of differences 701 and similarities across production and comprehension in the underly- 702 ing connectivity of the pars opercularis during competition resolution. 703 The PPI analyses were carried out in FSL using the methods described 704 in the FSL documentation. A mask of the pars opercularis cluster 705 obtained from the Stroop group results was used as the seed region. 706 First level analyses were carried out in FEAT for each of the tasks. The 707 average time course of the seed region was used as physiological vari- 708 able in the analysis of both the production and comprehension data. 709 In comprehension, the contrast high-competition > low-competition 710 was used as the psychological variable (using the contrast $1,-1$ ) 711 to examine interactions of our physiological regressor with levels 712 of competition. In the production task, the psychological variables 713 was the contrast of the high-competition condition with both the 714 low-competition condition and the reading control condition $(2,-1,715$ -1 ). The psychological regressor was convolved with the gamma func- 716 tion and temporal derivatives with temporal filtering added. The PPI 717 regressor was the interaction term between the zero-centered psy- 718 chological regressor and the de-meaned physiological regressor. 719 (Note that FSL differs from SPM in convolving the psychological re- 720 gressor, which is treated as nuisance variable in the interaction, rath- 721 er than deconvolving the physiological regressor. Although this has 722 been suggested to lead to loss of statistical power for event-related 723 designs, the results that do survive are nevertheless valid (Gitelman 724 Q10 et al., 2003).) To evaluate group statistics, including comparisons 725 across tasks, higher-level analyses were carried out on participants' 726 lower-level contrast parameter estimates using a threshold of 727 $\mathrm{p}<.001$ (uncorrected) and of $\mathrm{p}=.05$ (cluster corrected, $\mathrm{z}=2.3$ ). 728

\section{Results}

During the comprehension task, participants responded correctly 731 to the catch trials $90 \%$ of the time on average, indicating that they 732 maintained attention on the task. In the production task, participants 733 took $5.35 \mathrm{~s}$ on average to complete the fragments and took about 734 $2.60 \mathrm{~s}$ to read the fragments in the read-only control trials. Both 735 these measures are consistent with our behavioral results in Exp. 1. 736 Interestingly, there was a significant difference between the comple- 737 tion times of the high- and low-competition fragments, as measured 738 from the beginning of the trial $(M=5.58$ vs. $5.11 \mathrm{~s}, \mathrm{t}(16)=6.06,739$ $\mathrm{p}<.0001)$. In the Stroop localizer, we observed the typical competi- 740 tion effects in which incongruent trials, both eligible and ineligible, 741 elicited longer response times than the neutral trials ( $M$ incongruent 742 (eligible and ineligible $)=689 \mathrm{~ms}, \mathrm{M}$ neutral $=627 \mathrm{~ms}, \mathrm{t}(16)=743$ $2.17, \mathrm{p}<.05)$. Overall, the behavioral measures suggest that partici- 744 pants remained focused on the tasks at hand and followed the 745 instructions.

Whole brain results

To examine the extent to which the comprehension and production 748 networks overlap, we conducted whole brain analyses contrasting each 749 task vs. baseline or controls (cluster-corrected, $Z>2.3, \mathrm{p}<.05$ ). These 750 broad contrasts guarantee that potential commonalities across tasks 751 are not missed in more specific or direct contrasts, where common 752 activity may be canceled out. These analyses revealed that both sen- 753 tence comprehension and production recruited a wide network of 754 


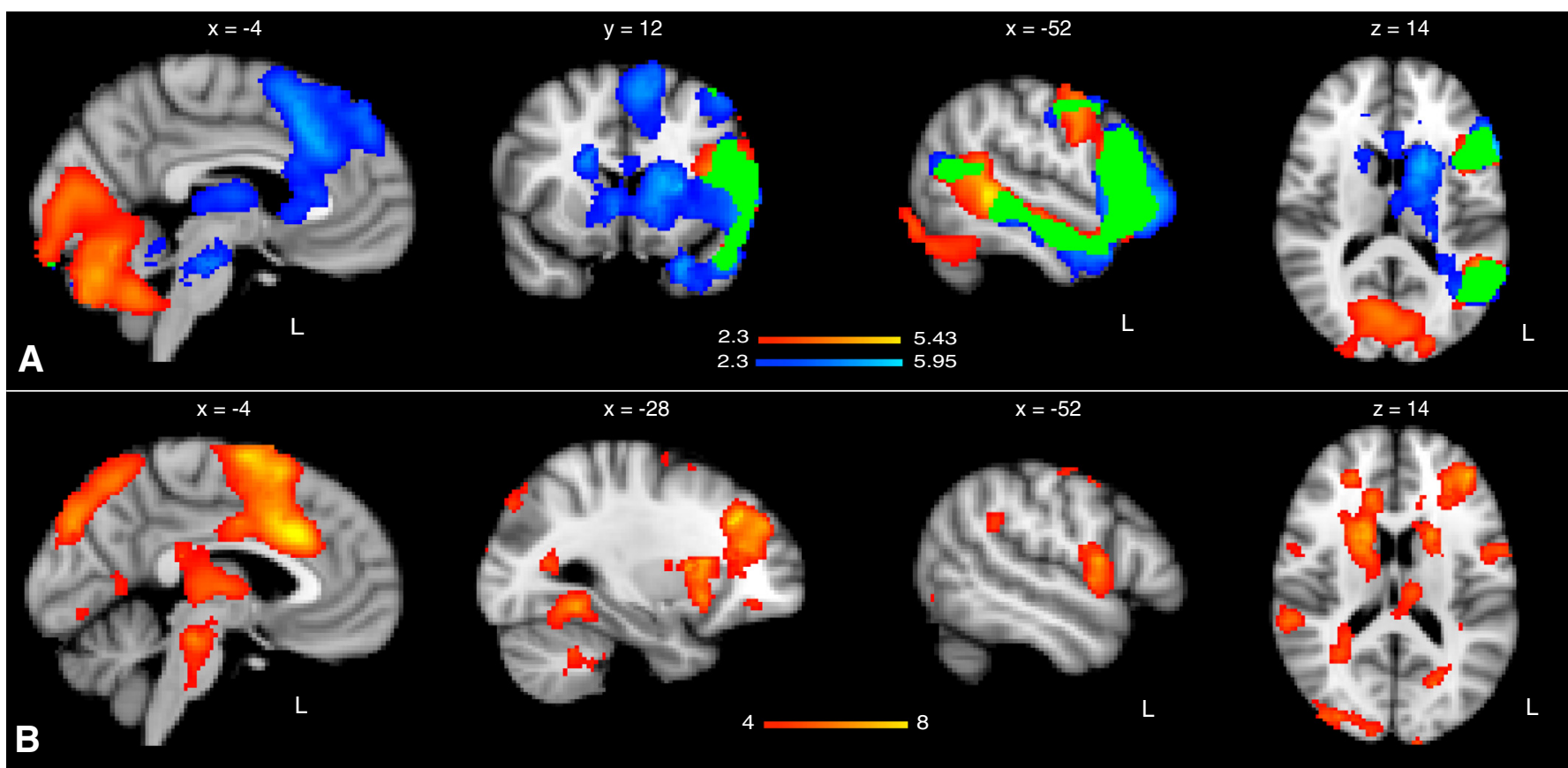

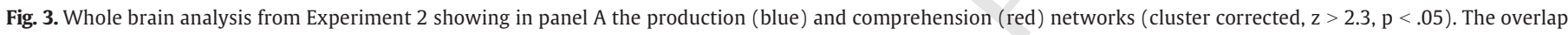

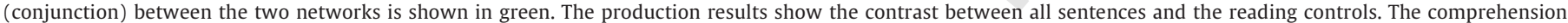
results show the contrast between all sentences vs. the visual baseline. Panel B shows in red the direct contrast production $>$ comprehension.

left-lateralised fronto-temporal areas. Fig. 3, panel A, shows the comprehension results in red, the production results in blue and the overlap between the two in green, which corresponds to a conjunction analysis as suggested by Nichols and colleagues (Nichols et al., 2005) (see also Table 3). Both tasks shared the involvement of several regions - the left inferior frontal gyrus (BA44, BA45, BA47), the precentral gyrus (BA6) and the posterior and anterior divisions of the middle temporal gyrus - although more extensive pMTG activity was found for comprehension. This is consistent with multiple studies reporting this core fronto-temporal network in language processing, which is thought to implement interactions between lexicosemantic retrieval and prefrontal control or competition processes (Gennari et al., 2007; Tyler and Marslen-Wilson, 2008; Whitney et al., 2011). However, the production task also recruited an additional network of medial structures, including the supplementary motor area (SMA, BA6), the anterior cingulate cortex (ACC), the caudate and the thalamus, which were not active during comprehension, as can be seen in Fig. 3. These regions have long been associated with production (Eickhoff et al., 2009; Ketteler et al., 2008; Murphy et al., 1997; Sörös et al., 2006; Turkeltaub et al., 2002; Wise et al., 1999), and the recruitment of the SMA and ACC in particular, is wellknown to play a critical role in response conflict or competition resolution in action and speech planning (Barch et al., 2000; Botvinick et al., 2004; Cohen et al., 2000; de Zubicaray et al., 2006; Mostofsky and Simmonds, 2008; Mukamel et al., 2010; Murphy et al., 1997; Simmonds et al., 2008; Tremblay and Small, 2011; Wilson et al., 2009).

Additionally, to determine the regions that were more active in one or another task, a higher-level analysis directly compared production vs. comprehension (cluster-corrected, $Z>2.3, \mathrm{p}<.05$ ). These contrasts revealed that the production task elicited more activity than comprehension in a wide network of regions, including the precentral gyrus, middle frontal gyrus and most medial frontal and subcortical structures mentioned above (see Fig. 3 panel B, Table 3 ). The contrast comparing comprehension $>$ production only showed more activation for comprehension in a portion of the temporal lobe and occipitotemporal structures associated with visual processing (see Table 3 ).
Overall, the pattern of results indicates that although a fronto-temporal 792 network is common to production and comprehension (with some 793 differences in activation levels across tasks in a portion of the poste- 794 rior temporal lobe), a more extensive network including motor con- 795 trol and planning regions is recruited in sentence production.

ROI results

To establish whether the high- and low-competition conditions 798 modulated activity within the Stroop-defined pars opercularis region 799 in both production and comprehension, we compared percent signal 800 change for each condition across participants, which was obtained 801 for each individual participant from contrasting each condition rela- 802 tive to its baseline or control within the 35 most active voxels in the 803 Stroop task (see Methods, region of interest analysis). We found a 804 similar pattern of results across the production and comprehension 805 tasks, as shown in Fig. 4. In comprehension, the activity elicited by 806 the high-competition items relative to baseline was higher than 807 that of the low-competition items relative to baseline $(M=.37,808$ $S E=.08 ; M=.28, S E=.05 ; \mathrm{t}(16)=2.31, \mathrm{p}=.03)$. Similarly, pro- 809 duction revealed higher activation for the high-competition condi- 810 tion than the low-competition condition relative to their read-only 811 controls $(M=.084, S E=.017 ; M=.069, S E=.014 ; \mathrm{t}(16)=2.90,812$ $\mathrm{p}=.01)$. Note that the overall mean activity in the production task is 813 much smaller than that of comprehension due to removal of common 814 reading activity (production minus reading-control contrast). Taken to- 815 gether, these results clearly suggest common mechanisms across tasks 816 operating at the level of each individual brain in the pars opercularis. 817

\section{PPI results}

To establish how the pars opercularis interacts with high vs. low 819 task demands in production and comprehension, we conducted PPI 820 analyses using this region as seed region. The results of the compre- 821 hension task revealed a stronger coupling of activity between pars 822 opercularis and the pMTG as a function of competition (uncorrected, 823 $\mathrm{p}=.001$ ), consistent with numerous studies indicating the involvement 824 
Table 3

Results from whole-brain analysis (cluster corrected, $\mathrm{p}<.05$ )

\begin{tabular}{|c|c|c|c|c|c|}
\hline \multirow[b]{2}{*}{ Contrasts } & \multirow[b]{2}{*}{ Brain area } & \multirow[b]{2}{*}{$Z$} & \multicolumn{3}{|c|}{ Voxel (MNI) } \\
\hline & & & $\mathrm{x}$ & $\mathrm{y}$ & $\mathrm{z}$ \\
\hline \multirow[t]{8}{*}{ Comprehension $>$ rest } & L IFG (BA44/BA45) & 5.01 & -50 & 14 & 24 \\
\hline & L IFG (BA 47) & 3.94 & -54 & 26 & -2 \\
\hline & L precentral G (BA6) & 5.03 & -46 & -2 & 32 \\
\hline & L PMTG (BA 32) & 5.81 & -52 & -44 & 2 \\
\hline & L MTG (BA 21) & 4.71 & -56 & -16 & -10 \\
\hline & L ATL (BA 21) & 4.18 & -50 & 14 & -22 \\
\hline & L hippocampus & 3.80 & -30 & -24 & -10 \\
\hline & L IPL (BA 39) & 3.07 & -36 & -60 & 44 \\
\hline \multirow[t]{16}{*}{ Production $>$ control } & L IFG (BA44/BA45) & 5.37 & -58 & 20 & 10 \\
\hline & L IFG (BA 47) & 4.21 & -54 & 34 & -12 \\
\hline & L precentral G (BA 6) & 2.65 & -54 & -4 & 48 \\
\hline & L MFG (BA 6) & 3.51 & -46 & 6 & 52 \\
\hline & L SFG (BA 9) & 4.28 & -10 & 56 & 38 \\
\hline & L SFG (BA 6) & 4.72 & -12 & 16 & 60 \\
\hline & L PSTG (BA39) & 3.47 & -44 & -62 & 16 \\
\hline & L MTG (BA 21) & 4.46 & -56 & -30 & -10 \\
\hline & L ATL (BA 21) & 4.52 & -50 & 12 & -30 \\
\hline & L ITG (BA 20) & 3.96 & -42 & -8 & -42 \\
\hline & L caudate & 4.43 & -16 & 12 & 12 \\
\hline & R caudate & 3.46 & 6 & 14 & 4 \\
\hline & L ACC (BA 32) & 4.49 & -10 & 26 & 32 \\
\hline & R ACC (BA 39) & 3.09 & 14 & 36 & 20 \\
\hline & Thalamus & 3.31 & -2 & -12 & 10 \\
\hline & R cerebellum & 4.23 & 36 & -58 & -40 \\
\hline \multirow[t]{13}{*}{ Production $>$ comprehension } & L ACC (BA 32) & 8.82 & -8 & 20 & 38 \\
\hline & R ACC (BA 32) & 8.98 & 4 & 20 & 30 \\
\hline & R SFG (BA6) & 8.79 & 12 & 6 & 62 \\
\hline & L SFG (BA6) & 7.66 & -8 & 2 & 68 \\
\hline & Precuneous & 7.11 & -10 & -80 & 42 \\
\hline & $\mathrm{R} / \mathrm{L}$ fusiform $\mathrm{G}$ & 7.79 & $+1-32$ & -48 & -12 \\
\hline & L MFG (BA 9) & 7.11 & -30 & 34 & 36 \\
\hline & $\mathrm{R} / \mathrm{L}$ insular cortex & 6.74 & $+/-30$ & 14 & -4 \\
\hline & L precentral G/insula & 6.17 & -46 & 6 & 2 \\
\hline & L precentral G (BA6) & 7.69 & -60 & 4 & 36 \\
\hline & $\mathrm{R} / \mathrm{L}$ caudate & 7.40 & $+/-18$ & 12 & 14 \\
\hline & $\mathrm{R} / \mathrm{L}$ putamen & 6.48 & -22 & 10 & 10 \\
\hline & $\mathrm{R} / \mathrm{L}$ cerebellum & 6.22 & $+/-36$ & -54 & -42 \\
\hline Comprehension $>$ production & L PMTG & 7.40 & -60 & -36 & 0 \\
\hline
\end{tabular}

Note: $\mathrm{L}=$ left hemisphere, $\mathrm{R}=$ right hemisphere, $\mathrm{IFG}=$ inferior frontal gyrus, PMTG $=$ posterior middle temporal gyrus, PSTG = posterior superior temporal gyrus, MTG = middle temporal gyrus, ITG = inferior temporal gyrus, ATL = anterior temporal lobe, $\mathrm{IPL}=$ inferior parietal lobe, MFG = middle frontal gyrus, SFG = superior frontal gyrus, $\mathrm{ACC}=$ anterior cingulate cortex.

of this fronto-temporal network in comprehension (see references above). The production results in contrast, indicated that a much more distributed network of regions was coupled with the pars opercularis as a function of competition (uncorrected, $\mathrm{p}=.001$ ).

PRODUCTION

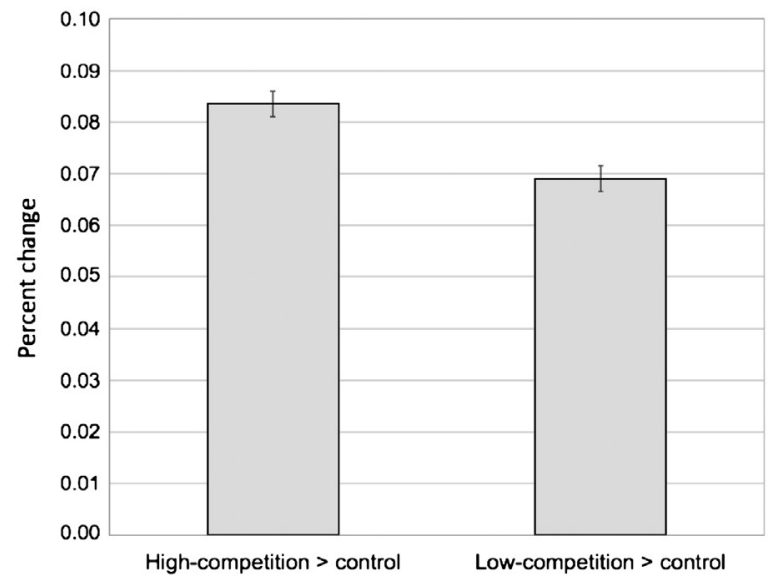

These results were stronger than those in comprehension, surviving 829 more stringent correction thresholds (cluster corrected $\mathrm{z}=2.3,830$ $\mathrm{p}=.05$ ) (see Fig. 5 and Table 4). This production network included 831 bilateral medial superior frontal gyrus, middle and superior tempo- 832 ral gyrus, left parietal cortex (postcentral gyrus and precuneus), in- 833 sular cortex and subcortical areas including the left basal ganglia, 834 thalamus and bilateral hippocampus. Some of the regions in this 835 network, particularly parietal and medial structures, survived cor- 836 rection thresholds when directly contrasting production and com- 837 prehension (production > comprehension), using the lower-level 838 contrast parameter estimates from the PPI analysis in a higher 839 level group analysis (uncorrected, $\mathrm{p}=.001$; see Table 4). All 840 these production regions have been typically shown to be involved 841 in speech planning, particularly when competitive processes are in- 842 volved, e.g., lexical selection (de Zubicaray et al., 2001, 2006; Eickhoff 843 et al., 2009; Heim et al., 2009; Murphy et al., 1997; Tremblay and Small, 844 2011; Whitney et al., 2008; Wilson et al., 2009; Wise et al., 1999). Note 845 that although the posterior temporal clusters show slightly different 846 centers for each task, there was considerable overlap, particularly if 847 the thresholds are lowered. This was despite the fact that reading 848 was removed from the completion task and thus potential common- 849 ly involved regions could have also been removed. This analysis 850 therefore, suggests that a similar portion of the posterior temporal 851 lobe is functionally connected to pars opercularis in both tasks 852 (see Tables 3 and 4). Overall, these results indicate that whereas 853 pars opercularis and portions of the posterior temporal cortex are 854 recruited by both sentence production and comprehension, the 855 network of regions effectively connected to pars opercularis is 856 quite different in each task.

\section{Discussion}

The present studies aimed to investigate whether sentence produc- 859 tion and comprehension share mechanisms of a competitive nature 860 within LIFG but differ in LIFG's supporting networks. Experiment 1861 indicated that both during reading comprehension and production 862 planning, readers and speakers take longer to process the high- 863 competition condition. Importantly, production planning times 864 were predicted by the number of alternative plans entertained in 865 the current context, just as reading times in comprehension corre- 866 late with the number of interpretations available in the unfolding 867 context (Gennari and MacDonald, 2008). These results suggest that 868 the processes taking place in our tasks involve competition between 869 alternative interpretations or plans, thus providing an appropriate 870 testing ground to examine the brain correlates of competition in 871 each task.

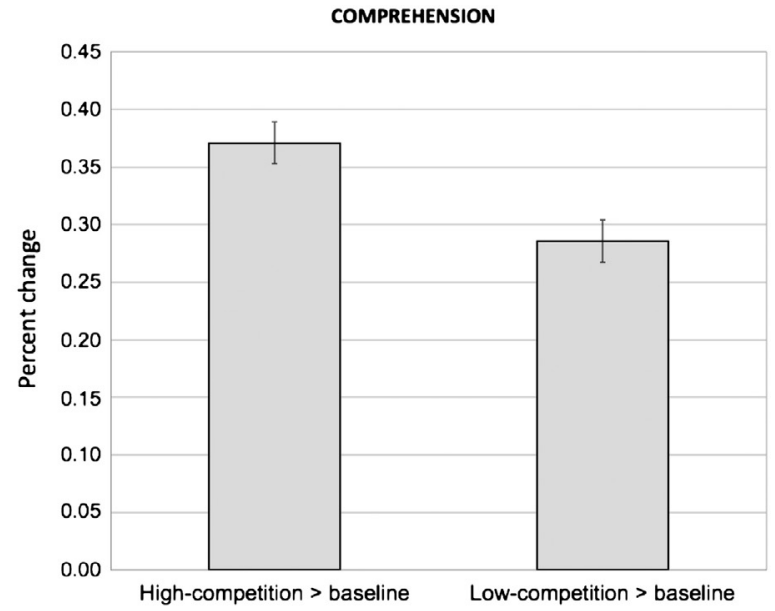

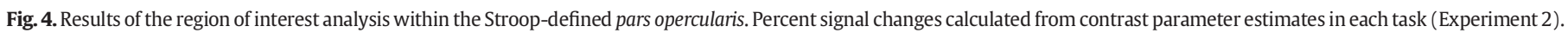
Relevant contrasts are indicated in the x-axis. Error bars indicate standard errors. 


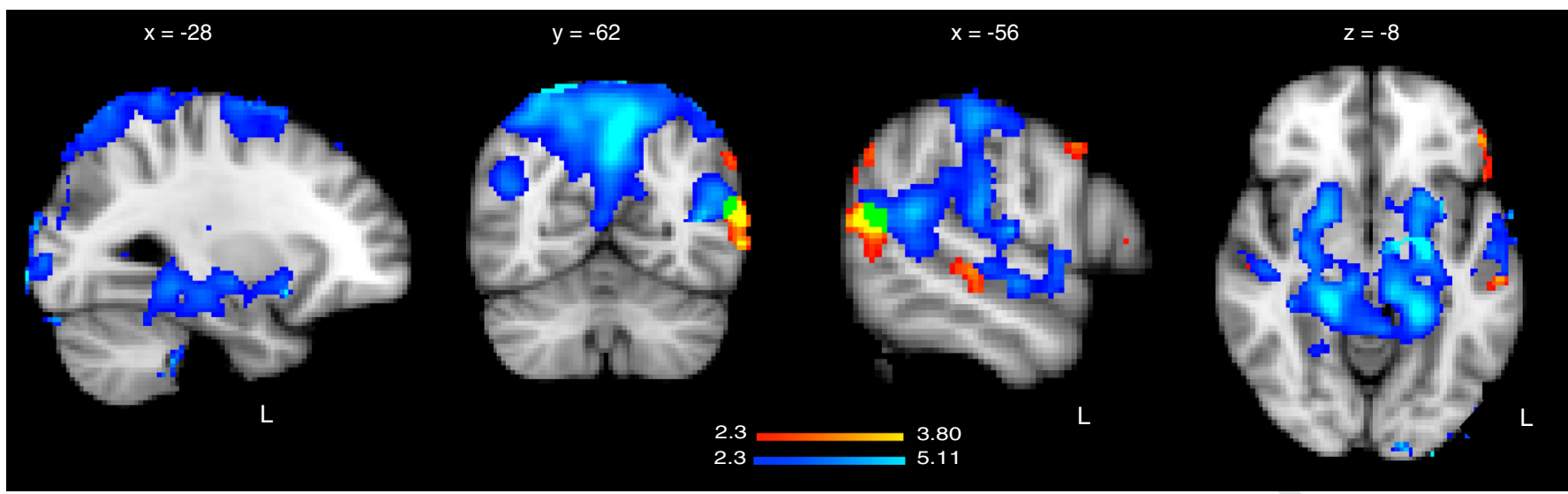

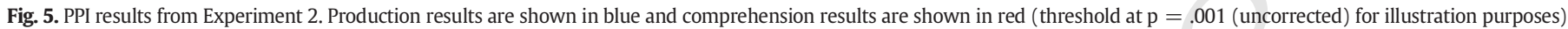
The green cluster indicates the overlap between production and comprehension.

Our fMRI experiment revealed several findings. Comparisons of the production and comprehension networks relative to rest or controls indicated that these tasks shared a fronto-temporal network, including LIFG and middle and superior temporal areas (Fig. 3). Within this network, the posterior temporal lobe is thought to store lexical knowledge, particularly that associated with verbs and their event structures (Bedny et al., 2008a; Dronkers et al., 2004; Humphreys et al., 2013; Tyler and Marslen-Wilson, 2008), whereas the pars opercularis is thought to perform general regulatory functions, including memory maintenance, controlled retrieval and encoding, integration and selection/inhibition (Barde and Thompson-Schill, 2002; D'Esposito et al., 1999; Fiebach et al., 2006; Fuster, 2001; Miller and Cohen, 2001; Thompson-Schill et al., 2005; Wagner et al., 2001). However, only production additionally engaged brain regions known to be critically involved in motor action control and/or speech planning, including the medial superior frontal regions (SMA), the ACC and subcortical regions such as caudate and putamen, all of which also

Table 4

Results from whole-brain PPI analysis. Regions showing an interaction between level of competition (high vs. low) and activity within BA44.

\begin{tabular}{|c|c|c|c|c|c|}
\hline \multirow[b]{2}{*}{ Task (contrast) } & \multirow[b]{2}{*}{ Brain area } & \multirow[b]{2}{*}{$Z$} & \multicolumn{3}{|c|}{ Voxel (MNI) } \\
\hline & & & $\mathrm{x}$ & $\mathrm{y}$ & z \\
\hline Comprehension (high > low) & L PMTG & 3.81 & -60 & -62 & 12 \\
\hline \multicolumn{6}{|l|}{ Production (high > low, control) } \\
\hline \multirow[t]{2}{*}{ Frontal } & R SFG & 3.90 & 24 & 12 & 60 \\
\hline & L SFG & 3.50 & -22 & -2 & 66 \\
\hline \multirow[t]{2}{*}{ Temporal } & L PMTG & 3.87 & -44 & -60 & 10 \\
\hline & L STG & 3.93 & -52 & -24 & 0 \\
\hline \multirow[t]{5}{*}{ Subcortical } & L caudate & 3.10 & -8 & 14 & -2 \\
\hline & L putamen & 3.43 & -22 & 4 & -10 \\
\hline & L hippocampus & 3.80 & -20 & -38 & -6 \\
\hline & $\mathrm{R}$ hippocampus & 3.67 & 18 & -34 & -8 \\
\hline & Thalamus & 4.01 & -4 & -8 & 4 \\
\hline \multirow[t]{2}{*}{ Parietal } & L postcentral G & 3.78 & -42 & -36 & 68 \\
\hline & L precuneus & 4.01 & -4 & -66 & 50 \\
\hline Sub-lobar & $\mathrm{L}$ insular cortex & 3.56 & -32 & 12 & -10 \\
\hline \multirow{7}{*}{$\begin{array}{l}\text { Production }(\text { high }>\text { low, } \\
\text { control) }>\text { comprehension } \\
(\text { high }>\text { low })\end{array}$} & L IPL & 3.44 & -62 & -24 & 26 \\
\hline & L precentral G & 2.56 & -62 & 4 & 12 \\
\hline & $\mathrm{R} / \mathrm{L}$ MFG & 2.64 & -32 & 38 & 26 \\
\hline & L SFG & 2.59 & -14 & 0 & 60 \\
\hline & R ACC & 2.6 & 6 & 36 & 16 \\
\hline & R SFG & 2.6 & 18 & 14 & 64 \\
\hline & R MFG & 3.2 & 30 & 4 & 56 \\
\hline
\end{tabular}

Note: $\mathrm{L}=$ left hemisphere, $\mathrm{R}=$ right hemisphere, $\mathrm{PMTG}=$ posterior middle temporal gyrus, STG = superior temporal gyrus, SFG = superior frontal gyrus, IPL = inferior parietal lobe, $\mathrm{MFG}=$ middle frontal gyrus. emerged from direct contrasts across tasks (Alario et al., 2006; 890 Barch et al., 2000; Botvinick et al., 2004; Chen et al., 2009; Ketteler 891 et al., 2008; Mukamel et al., 2010; Murphy et al., 1997; Nachev 892 et al., 2007; Simmonds et al., 2008; Sörös et al., 2006; Wahl et al., 893 2008; Wise et al., 1999).

Critically, competition conditions modulated activity for both 895 tasks in the Stroop-defined pars opercularis, which targeted repre- 896 sentational conflict, suggesting common competitive mechanisms. 897 The strength and the extent of the LIFG's functional coupling, 898 however, differed across tasks. Indeed, PPI analyses revealed that 899 the pars opercularis established distinct patterns of connectivity in 900 production compared to comprehension as a function of condition 901 (Fig. 5). Incomprehension, high competition compared to low competi- 902 tion resulted in increased connectivity with the posterior temporal lobe. 903 In contrast, high competition in production resulted in increased con- 904 nectivity with additional regions relative to comprehension, such as 905 the medial superior frontal gyrus (SMA), parietal lobe, basal ganglia 906 structures such as the caudate, and the hippocampus, although these 907 subcortical structures did not survive correction in the direct contrast 908 between production and comprehension for these analyses. The SMA 909 and these subcortical structures, particularly the caudate, are involved 910 in motor/speech planning, as indicated above, as is the parietal lobe 911 (Brownsett and Wise, 2010; Geranmayeh et al., 2012), whereas the 912 hippocampus is well known to serve memory retrieval (Nadel and 913 Moscovitch, 2001; Paller and Wagner, 2002; Whitney et al., 2008). 914 These results therefore suggest that high levels of competition in pro- 915 duction cause reverberations across a much wider network of regions 916 compared to comprehension, specifically recruiting regions associated 917 with motor response conflict and possibly, memory retrieval. $\quad 918$

Production and comprehension thus appear as clearly distinct tasks 919 in respect of the functional networks recruited for task performance 920 in connection with pars opercularis, in line with psycholinguistic 921 approaches, but they appear to share mechanisms of a competitive 922 nature within pars opercularis and the posterior temporal lobe. This 923 finding is consistent with numerous comprehension and production 924 studies reporting activity in pars opercularis and the posterior temporal 925 lobe (de Zubicaray et al., 2006; Gennari et al., 2007; Menenti et al., 2011; 926 Tremblay and Small, 2011), as well as neuropsychological and TMS 927 studies reporting either production or comprehension impairments 928 when these regions are damaged or stimulated (Jefferies and Lambon 929 Ralph, 2006; Spalek and Thompson-Schill, 2008; Thompson-Schill et al., 930 2002; Whitney et al., 2011). These common fronto-temporal regions 931 thus operate together in both tasks, particularly when conflicting 932 information is activated, and are involved in storing long-term asso- 933 ciations between words, structures and their meanings (linguistic 934 knowledge) and computing their higher order contingencies in 935 
sentence processing. Yet, production and comprehension handle linguistic knowledge differently by igniting associations in different regions. Production in particular may involve additional processes such as the resolution of competition between alternative plans in motor-related regions.

These results, together with behavioral studies, illuminate the nature of the processes that might be common or distinct in production and comprehension. Common processes may include the cue-based predictions and competition mechanisms suggested by Experiment 1 , which have also been extensively investigated in the psycholinguistic literature (Altmann and Kamide, 1999; DeLong et al., 2005; Pickering and Garrod, 2007). Many reading studies for example indicate that comprehension difficulty is predicted by distributional probabilities in English corpora, and in particular, by the degree of fit between upcoming material and its probability of occurring in the preceding context, with poor fit leading to comprehension difficulty (Gennari and MacDonald, 2008, 2009; Hale, 2006; Levi, 2008; Lewis and Vasishth, 2005; MacDonald et al., 1994; Smith and Levy, 2013; Tanenhaus and Trueswell, 1995; Trueswell et al., 1994). This suggests that alternative continuations are entertained as the reading proceeds, leading to competition and inhibition processes. Similarly, our production study indicates that the number of alternative sentence continuations, as measured by overall preferences across speakers, predicts production planning times, suggesting that a greater number of available choices leads to greater difficulty and competition. These observations are consistent with the general executive functions often attributed to portions of LIFG and prefrontal cortex in general in that they mediate contingencies between cues and their associations, regardless of whether these cues are internally or externally generated (Fuster, 2001; Koechlin and Jubault, 2006; Passingham et al., 2000). The pars opercularis in particular is indeed involved in establishing linguistic contingencies during language learning (Opitz and Friederici, $2003,2004)$ and it is necessary for producing word sequences and comprehending word order, grammatical cues and grammatical relations (Caplan et al., 1996; Thothathiri et al., 2010). Therefore, the pars opercularis and its interactive networks may manage linguistic contingencies, and thus, the anticipation or activation of information associated with the current task context.

The production-specific areas of activity reported here likely reflect production-specific processes such as word or structure retrieval, and linguistic and articulatory planning (or sub-vocalization), which nevertheless appear to involve competition as a result of the semantic properties of the context. Indeed, despite the lack of temporal resolution in fMRI, the fact that the level of competition modulates the interaction of pars opercularis with motor-related regions suggests that semantic competition percolates to putatively lower levels of phonological or articulatory planning. Thus, competition resolution does not appear restricted to word selection or semantic-role assignment, but instead, reverberates across a large network involving linguistic representations at different levels, syntactic, phonological, and articulatory. For example, it is possible that the alternative utterances entertained by the speakers do not only take place at a semantic level but also at the level of the phonological forms or motor plans associated with the different alternatives. Thus the finding that the influence of semantic competition pervades the production network challenges serial/ encapsulated models of sentence production that argue for distinctive stages of lexical retrieval, planning and word sequencing (Bock and Levelt, 1994) and instead, suggests parallel processing and interactivity across an extensive network.

Our results have implications for models of language processing discussed in the literature such as dual-stream models. These models argue that there are dorsal and ventral streams in language processing, with different networks being engaged as a function of task, although they differ in the specific functional roles assigned to the individual regions within the streams (Friederici, 2009; Hickok and Poeppel, 2004, 2007; Petrides and Pandya, 2009; Saur et al., 2008;
Wilson et al., 2011). The ventral stream including the fronto-temporal 1002 network is thought to be responsible for mapping sounds (and letters) 1003 to meaning, whereas the dorsal stream including the temporo- 1004 parietal junction and motor structures is thought to be involved in 1005 syntactic processing and in mapping sounds to action. This broad 1006 characterization is supported by what is known about the white 1007 matter tracts connecting sensory processing regions in posterior cor- 1008 tex to frontal cortex, with ventral and dorsal tracts converging in 1009 pre-frontal cortex (Anwander et al., 2007; Frey et al., 2008). Our re- 1010 sults are broadly consistent with these processing routes but addi- 1011 tionally suggest a potential common role of the fronto-temporal 1012 network in both production and comprehension.

More generally, together with existing literature, these results 1014 highlight the importance of understanding functional networks in 1015 the context of tasks demands, rather than focusing on a region's 1016 common role across tasks. Clearly, competition resolution must be 1017 achieved by the critical contribution of the interactive network at 1018 hand, and no single region is solely responsible for competition res- 1019 olution. Indeed, many studies and reviews have suggested that pars 1020 opercularis is involved in a great variety of tasks, including perceptual 1021 decisions, response conflict resolution (e.g., Stroop task), working 1022 memory, memory retrieval and language processing (Crittenden and 1023 Duncan, 2012; Duncan, 2010; Duncan and Owen, 2000; Wagner et al., 1024 2001). Across these tasks, verbal stimuli additionally engage temporal 1025 regions whereas goal and response-oriented tasks additionally engage 1026 parietal regions (Cisek, 2007; Duncan, 2010; Duncan and Owen, 2000; 1027 Tyler and Marslen-Wilson, 2008). These findings suggest that the net- 1028 works engaged in each case is determined by stimulus characteristics 1029 and task demands and challenges attempts to attribute a given region 1030 such as the pars opercularis a unique specific function across all tasks. 1031 In the present study, the tightly controlled nature of our stimuli and be- 1032 havioral results suggest that at least some aspects of evaluating alterna- 1033 tives within the common fronto-temporal network is likely to be shared 1034 by both production and comprehension, but this does not preclude that 1035 these fronto-temporal regions, and pars opercularis in particular, play a 1036 different role in the context of other task networks. In fact, the mere fact 1037 that pars opercularis in our results, interacts with more regions in one 1038 task than another suggests that at a neuronal level there must be 1039 some task differences with respect to the information being handled 1040 in this region and perhaps, the timing of activation across different 1041 regions. Establishing an adequate level of functional description with 1042 fMRI, which lacks temporal resolution, remains one of the main chal- 1043 lenges in cognitive neuroscience.

Finally, note that our study specifically targeted LIFG, and found that 1045 the pars opercularis, which most strongly responded to the representa- 1046 tional conflict in the Stroop task, was also sensitive to generally assumed 1047 competition processes both in production and comprehension. Howev- 1048 er, these findings do not preclude that other regions activated by both 1049 tasks (see Fig. 3) are also sensitive to competition processes, since we 1050 have not probed each one in turn. This is particularly the case for the 1051 pars triangularis and possibly pars orbitalis, which were also commonly 1052 activated by the two tasks. Moreover, our localizer only targeted 1053 word-level competition, and it is possible that sentence level competi- 1054 tion requires additional portions of the pre-frontal cortex. Thus, more 1055 research is required to address this issue and further delineate the role 1056 of regions common to both tasks.

In sum, sentence production and reading comprehension appear 1058 to share competition mechanisms in a fronto-temporal network typ- 1059 ically engaged in language processing. This network appears to man- 1060 age the myriad of activations elicited by various types of linguistic 1061 cues, including the association between noun meanings and their 1062 event roles in a sentence. However, production recruits several addi- 1063 tional regions to retrieve information and generate linguistically- 1064 based plans. Therefore, competition in production and comprehen- 1065 sion reverberates across distinct functional networks, as determined 1066 by task demands. 


\section{Acknowledgments}

This work was supported by research funds of the Department of Psychology, University of York. We thank Lauren Henshall and staff at the York Neuroimaging Centre for help with data collection and technical support. We also thank Nick Hindy and colleagues for sharing the Stroop task used in this work.

\section{References}

Adank, P., 2012. Design choices in imaging speech comprehension: an Activation Likelihood Estimation (ALE) meta-analysis. Neuroimage 63, 1601-1613.

Alario, F.-X., Chainay, H., Lehericyc, S., Cohen, L., 2006. The role of the supplementary motor area (SMA) in word production. Brain Res. 1076, 129-143.

Almann, G.T.M., Kamide, Y., 1999. Incremental interpretation at verbs: restricting the domain of subsequent reference. Cognition 73, 247-264.

Amunts, K., Lenzen, M., Friederici, A.D., Schleicher, A., Morosan, P., Palomero-Gallagher, N., Zilles, K., 2010. Broca's region: novel organizational principles and multiple receptor mapping. PLoS Biol. 8, e1000489.

Anwander, A., Tittgemeyer, M., von Cramon, D.Y., Friederici, A.D., Konsche, T.R., 2007 Connectivity-based parcellation of Broca's area. Cereb. Crotex 17.

Barch, D.M., Braver, T.S., Sabb, F.W., Noll, D.C., 2000. Anterior cingulate and the monitoring of response conflict: evidence from an fMRI study of overt verb generation. J. Cogn. Neurosci. 12, 298-309.

Barde, L.H., Thompson-Schill, S.L., 2002. Models of functional organization of the lateral prefrontal cortex in verbal working memory: evidence in favor of the process model. J. Cogn. Neurosci. 14, 1054-1063.

Bedny, M., Caramazza, A., Grossman, E., Pascual-Leone, A., Saxe, R., 2008a. Concepts are more than percepts: the case of action verbs. J. Neurosci. 28, 11347-11353.

Bedny, M., McGill, M., Thompson-Schill, S.L., Bedny, M., McGill, M., Thompson-Schill, S.L., 2008b. Semantic adaptation and competition during word comprehension. Cereb. Cortex 18, 2574-2585.

Bock, K., Levelt, W., 1994. Language production: grammatical encoding. In: Gernsbacher, M.A. (Ed.), Handbook of Psycholinguistics. Academic Press, San Diego, CA.

Bock, K., Dell, G.S., Chang, F., Onishi, K.H., 2007. Persistent structural priming from language comprehension to language production. Cognition 104, 437-458.

Botvinick, M.M., Cohen, J.D., Carter, C.S., 2004. Conflict monitoring and anterior cingulate cortex: an update. Trends Cogn. Sci. 8, 539-546.

Brownsett, S.L., Wise, R.J., 2010. The contribution of the parietal lobes to speaking and writing. Cereb. Cortex 20, 517-523.

Buchweitz, A., Mason, R.A., Tomitch, L.M.B., Just, M.A., 2009. Brain activation for reading and listening comprehension: an fMRI study of modality effects and individual differences in language comprehension. Psychol. Neurosci. 2, 111-123.

Caplan, D., Hildebrandt, N., Makris, N., 1996. Location of lesions in stroke patients with deficits in syntactic processing in sentence comprehension. Brain 119, 933-949.

Caplan, D., Stanczak, L., Waters, G., 2008. Syntactic and thematic constraint effects on blood oxygenation level dependent signal correlates of comprehension of relative clauses. J. Cogn. Neurosci. 20, 643-656.

Chang, F., Dell, G.S., Bock, K., 2006. Becoming syntactic. Psychol. Rev. 113, 234-272.

Chein, J.M., Fissellc, K., Jacobsd, S., Fiez, J.A., 2002. Functional heterogeneity within Broca's area during verbal working memory. Physiol. Behav. 77, 635-639.

Chen, E., West, C., Waters, G., Caplan, D., 2006. Determinants of BOLD signal correlates of processing object-extracted relative clauses. Cortex 42, 591-604.

Chen, C.Y., Muggleton, N.G., Tzeng, O.J., Hung, D.L., Juan, C.H., 2009. Control of prepotent responses by the superior medial frontal cortex. Neuroimage 44, 537-545.

Cisek, P., 2007. Cortical mechanisms of action selection: the affordance competition hypothesis. Philos. Trans. R. Soc. Lond. B Biol. Sci. 362, 1585-1599.

Cohen, J.D., Botvinick, M., Carter, C.S., 2000. Anterior cingulate and prefrontal cortex: who's in control? Nat. Neurosci. 3, 421-423.

Costa, A., Alario, F.X., Caramazza, A., 2005. On the categorical nature of the semantic interference effect in the picture-word interference paradigm. Psychon. Bull. Rev. 12, 125-131.

Crittenden, B.M., Duncan, J., 2012. Task difficulty manipulation reveals multiple demand activity but no frontal lobe hierarchy. Cereb. Cortex.

Dapretto, M., Bookheimer, S.Y., 1999. Form and content: dissociating syntax and semantics in sentence comprehension. Neuron 24, 427-432.

de Zubicaray, G.I., Wilson, S.J., McMahon, K.L., Muthiah, S., 2001. The semantic interference effect in the picture-word paradigm: an event-related fMRI study employing overt responses. Hum. Brain Mapp. 14, 218-227.

de Zubicaray, G.I., McMahon, K.L., Eastburn, M.M., Pringle, A., 2006. Top-down influences on lexical selection during spoken word production: a 4T fMRI investigation of refractory effects in picture naming. Hum. Brain Mapp. 27, 864-873.

DeLong, K.A., Urbach, T.P., Kutas, M., 2005. Probabilistic word pre-activation during language comprehension inferred from electrical brain activity. Nat. Neurosci. 8, 1117-1121.

D'Esposito, M., Postle, B.R., Jonides, J., Smith, E.E., 1999. The neural substrate and temporal dynamics of interference effects in working memory as revealed by event-related functional MRI. Proc. Natl. Acad. Sci. U. S. A. 96, 7514-7519.

Dronkers, N.F., Wilkins, D.P., Van Valin Jr., R.D., Redfern, B.B., Jaeger, J.J., 2004. Lesion analysis of the brain areas involved in language comprehension. Cognition 92, 145-177.

Duffy, S.A., Morris, R.K., Rayner, K., 1988. Lexical ambiguity and fixation times in reading. J. Mem. Lang. 27, 429-446.
Duncan, J., 2010. The multiple-demand (MD) system of the primate brain: mental pro- 1147 grams for intelligent behaviour. Trends Cogn. Sci. 14, 172-179. 1148

Duncan, J., Owen, A.M., 2000. Common regions of the human frontal lobe recruited by 1149 diverse cognitive demands. Trends Neurosci. 23, 475-482.

Eickhoff, S.B., Heim, S., Zilles, K., Amunts, K., 2009. A systems perspective on the effective 1151 connectivity of overt speech production. Philos. Trans. R. Soc. Lond. A Math. Phys. Eng. 1152 Sci. 367, 2399-2421.

Fedorenko, E., Hsieh, P.J. Nieto-Castañón, A Whitfield-Gabrieli, S., Kanwisher, N., 2010. 1154 New method for fMRI investigations of language: defining ROIs functionally in indi- 1155 vidual subjects. J. Neurophysiol. 104, 1177-1194.

Fedorenko, E., Duncan, J., Kanwisher, N., 2012. Language-selective and domain- 1157 general regions lie side by side within Broca's area. Curr. Biol. 22, 2059-2062. 1158

Ferreira, F.S., Slevc, L.R., Rogers, E.S., 2005. How do speakers avoid ambiguous linguistic 1159 expressions? Cognition 96, 263-284.

Fiebach, C.J. Rissman, J. D'Esposito, M. 2006. Modulation of inferotemporal cortex activa- 1161 tion during verbal working memory maintenance. Neuron 51, 251-261. 1162

Frey, S., Campbell, J.S.W., Pike, G.B., Petrides, M., 2008. Dissociating the human language 1163 pathways with high angular resolution diffusion fiber tractography. J. Neurosci. 28, 1164 11435-11444.

Friederici, A.D., 2009. Pathways to language: fiber tracts in the human brain. Trends Cogn. 1166 Neurosci. 13, 175-181. 1167

Fuster, J.M., 2001. The prefrontal cortex-an update: time is of the essence. Neuron 30, 1168 319-333.

Garrett, M.F., 1980. Levels of processing in sentence production. In: Butterworth, B. (Ed.), 1170 Language Production. Academic Press, London, pp. 177-220. 1171

Gennari, S.P., MacDonald, M.C., 2008. Semantic indeterminacy in object relative clauses. 1172 J. Mem. Lang. 58, 161-187.

Gennari, S.P., MacDonald, M.C., 2009. Linking production and comprehension processes: 1174 the case of relative clauses. Cognition 111, 1-23.

Gennari, S.P., MacDonald, M.C., Postle, B.R., Seidenberg, M.S., 2007. Context-dependent 1176 interpretation of words: evidence for interactive neural processes. Neuroimage 35, 1177 1278-1286.

Gennari, S.P., Mirkovic, J., MacDonald, M.C., 2012. Animacy and competition in relative 1179 clause production: a cross-linguistic investigation. Cogn. Psychol. 65, 141-176. 1180

Geranmayeh, F., Brownsett, S.L., Leech, R., Beckmann, C.F., Woodhead, Z., Wise, R.J., 2012. 1181 The contribution of the inferior parietal cortex to spoken language production. Brain 1182 Lang. 121, 47-57.

Glezer, L.S., Riesenhuber, M., 2013. Individual variability in location impacts orthographic 1184 selectivity in the "visual word form area". J. Neurosci. 33, 11221-11226.

Hagoort, P., 2005. On Broca, brain, and binding: a new framework. Trends Cogn. Sci. 9, 1186 $416-423$.

Hale, J., 2006. Uncertainty about the rest of the sentence. Cogn. Sci. Multidiscip. J. 30, 1188 643-672.

Heim, S., Eickhoff, S.B., Friederici, A.D., Amunts, K., 2009. Left cytoarchitectonic area 441190 supports selection in the mental lexicon during language production. Brain Struct. 1191 Funct. 213, 441-456.

Hickok, G., Poeppel, D., 2004. Dorsal and ventral streams: a framework for understanding 1193 aspects of the functional anatomy of language. Cognition 92, 67-99. 1194

Hickok, G., Poeppel, D., 2007. The cortical organization of speech processing. Nat. Rev. 1195 Neurosci. 8, 393-402.

Hindy, N.C., Altmann, G.T.M., Kalenika, E., Thompson-Schill, S.L., 2012. The effect of object 1197 state-changes on event processing: do objects compete with themselves? J. Neurosci. 1198 $32,5795-5803$.

Huang, J., Carr, T.H., Cao, Y., 2001. Comparing cortical activations for silent and overt 1200 speech using event-related fMRI. Hum. Brain Mapp. 15, 39-53.

Humphreys, G.F., Newling, K., Jennings, C., Gennari, S.P., 2013. Motions and actions in 1202 language: semantic representations in occipito-temporal cortex. Brain Lang. 125, 1203 94-105.

Indefrey, P., 2011. The spatial and temporal signatures of word production components: a 1205 critical update. Front. Psychol. 255.

January, D., Trueswell, J.C., Thompson-Schill, S.L., January, D., Trueswell, J.C., Thompson- 1207 Schill, S.L., 2009. Co-localization of stroop and syntactic ambiguity resolution in 1208 Broca's area: implications for the neural basis of sentence processing. J. Cogn. 1209 Neurosci. 21, 2434-2444.

Jefferies, E., Lambon Ralph, M.A., 2006. Semantic impairment in stroke aphasia versus se- 1211 mantic dementia: a case-series comparison. Brain 129, 2132-2147. 1212

Jenkinson, M., Bannister, P., Brady, M., Smith, S., 2002. Improved optimisation for the 1213 robust and accurate linear registration and motion correction of brain images. 1214 Neuroimage 17, 825-841.

Jobard, G., Vigneau, M., Mazoyer, B., Tzourio-Mazoyer, N., 2007. Impact of modality 1216 and linguistic complexity during reading and listening tasks. Neuroimage 34, 1217 784-800. 1218

Josephs, O., Henson, R.N., 1999. Event-related functional magnetic resonance imaging: 1219 modelling, inference and optimization. Philos. Trans. R. Soc. Lond. B Biol. Sci. 354, 1220 $1215-1228$.

Juch, H., Zimine, I., Seghier, M., Lazeyras, F., Fasel, J.H.D., 2005. Anatomical variability of the 1222 lateral frontal lobe surface: implication for intersubject variability in language 1223 neuroimage. Neuroimage 24, 504-514.

Ketteler, D., Kastrau, F., Vohn, R., Huberd, W., 2008. The subcortical role of language 1225 processing. High level linguistic features such as ambiguity-resolution and the 1226 human brain; an fMRI study. Neuroimage 39, 2002-2009. 1227

Koechlin, E., Jubault, T., 2006. Broca's area and the hierarchical organization of human 1228 behavior. Neuron 50, 963-974.

Levelt, W.J.M., Roelofs, A., Meyer, A.S., 1999. A theory of lexical access in speech produc- 1230 tion. Behav. Brain Sci. 22, 1-75.

Levi, R., 2008. Expectation-based syntactic comprehension. Cognition 106, 1126-1177. 1232 
Saxe, R., Brett, M., Kanwisher, N., 2006. Divide and conquer: a defense of functional 1309 localizers. Neuroimage 30, 1088-1096. memory retrieval. Cognit. Sci. 29, 375-419.

indenberg, R., Scheef, L., 2007. Supramodal language comprehension: role of the left temporal lobe for listening and reading. Neuropsychologia 45, 2407-2415.

MacDonald, M.C., 1999. Distributional information in language comprehension, production, and acquisition: three puzzles and a moral. In: MacWhinney, B. (Ed.), The Emergence of Language. Erlbaum, Mahweh, NJ.

MacDonald, M.C., Pearlmutter, N., Seidenberg, M., 1994. Lexical nature of syntactic ambiguity resolution. Psychol. Rev. 101, 676-703.

Mak, W.M., Vonk, W., Schriefers, H., 2002. The influence of animacy on relative clause processing. J. Mem. Lang. 47, 50-68.

Mak, W.M., Vonk, W., Schriefers, H., 2006. Animacy in processing relative clauses: the hikers that rocks crush. J. Mem. Lang. 54, 466-490.

Menenti, L., Gierhan, S.M.E., Segaert, K., Hagoort, P., 2011. Shared language: overlap and segregation of the neuronal infrastructure for speaking and listening revealed by functional MRI. Psychol. Sci. 22, 1173-1182.

Michael, E.B., Keller, T.A., Carpenter, P.A., Just, M.A., 2001. fMRI investigation of sentence comprehension by eye and by ear: modality fingerprints on cognitive processes. Hum. Brain Mapp. 13, 239-252.

Milham, M.P., Banich, M.T., Webb, A., Barad, V., Cohen, N.J., Wszalek, T., Kramer, A.F., 2001. The relative involvement of anterior cingulate and prefrontal cortex in attentional control depends on nature of conflict. Cogn. Brain Res. 12, 467-473.

Miller, E.K., Cohen, J.D., 2001. An integrative theory of prefrontal cortex function. Annu. Rev. Neurosci. 24, 167-202.

Mostofsky, S.H., Simmonds, D.J., 2008. Response inhibition and response selection: two sides of the same coin. J. Cogn. Neurosci. 20, 751-761.

Mukamel, R., Ekstrom, A.D., Kaplan, J., lacoboni, M., Fried, I., 2010. Single-neuron responses in humans during execution and observation of actions. Curr. Biol. 20, 750-756.

Murphy, K., Corfield, D.R., Guz, A., Fink, G.R., Wise, R.J., Harrison, J., Adams, L., 1997. Cerebral areas associated with motor control of speech in humans. J. Appl. Physiol. $83,1438-1447$

Nachev, P., Wydell, H., O'Neill, K., Husain, M., Kennard, C., 2007. The role of the presupplementary motor area in the control of action. Neuroimage 36, T155-T163.

Nadel, L., Moscovitch, M., 2001. The hippocampal complex and long-term memory revisited. Trends Cogn. Neurosci. 228-230.

Nichols, M., Brett, M., Andersson, J., Wager, T., Poline, J.-B., 2005. Valid conjunction inference with the minimum statistic. Neuroimage 25, 653-660.

Nieto-Castañón, A., Fedorenko, E., 2012. Subject-specific functional localizers increase sensitivity and functional resolution of multi-subject analyses. Neuroimage 63 1646-1669.

Novick, J.M., Trueswell, J.C., Thompson-Schill, S.L., 2005. Cognitive control and parsing: reexamining the role of Broca's area in sentence comprehension. Cogn. Affect. Behav. Neurosci. 5, 263-281.

Novick, J.M., Kan, I.P., Trueswell, J.C., Thompson-Schill, S.L., Novick, J.M., Kan, I.P., Trueswell, J.C., Thompson-Schill, S.L., 2009. A case for conflict across multiple domains: memory and language impairments following damage to ventrolateral prefrontal cortex. Cogn. Neuropsychol. 26, 527-567.

Opitz, B., Friederici, A.D., 2003. Interactions of the hippocampal system and the prefrontal cortex in learning language-like rules. Neuroimage 19, 1730-1737.

Opitz, B., Friederici, A.D., 2004. Brain correlates of language learning: the neuronal dissociation of rule-based versus similarity-based learning. J. Neurosci. 24 8436-8440.

Paller, K.A., Wagner, A.D., 2002. Observing the transformation of experience into memory. Trends Cogn. Sci. 6, 93-102.

Passingham, R.E., Toni, I., Rushworth, M.F., 2000. Specialisation within the prefrontal cortex the ventral prefrontal cortex and associative learning. Exp. Brain Res. 133, 103-113.

Petrides, M., 2005. Lateral prefrontal cortex: architectonic and functional organization. Phil. Trans. R. Soc. B 360, 781-795.

Petrides, M., Pandya, D.N., 2009. Distinct parietal and temporal pathways to the homologues of Broca's area in the monkey. PLoS Biol. 7, e1000170.

Pickering, M.J., Garrod, S., 2007. Do people use language production to make predictions during comprehension? Trends Cogn. Sci. 11, 105-110.

Rayner, K., Duffy, S., 1986. Lexical complexity and fixation times in reading: effects of word frequency, verb complexity, and lexical ambiguity. Mem. Cognit. 14, 191-201.

Rayner, K., Carlson, M., Frazier, L., 1983. The interaction of syntax and semantics during sentence processing: eye movements in the analysis of semantically biased sentences. J. Verbal Learn. Verbal Behav. 22, 358-374.

Rodd, J.M., Davis, M.H., Johnsrude, I.S., 2005. The neural mechanisms of speech comprehension: fMRI studies of semantic ambiguity. Cereb. Cortex 15, 1261-1269.

odd, J.M., Longeb, O.A., Randall, B., Tyler, L.K., 2010. The functional organisation of the ronto-temporal language system: evidence from syntactic and semantic ambiguity. Neuropsychologia 48, 1324-1335.

Saur, D., Kreher, B.W., Schnell, S., Kummerer, D., Kellmeyer, P., Vry, M.-S., Umarova, R., Musso, M., Glauche, V., Abel, S., Huber, W., Rijntjes, M., Hennig, J., Weiller, C. 2008. Ventral and dorsal pathways for language. Proc. Natl. Acad. Sci. U. S. A. 105 $18035-18040$
Seidenberg, M.S., MacDonald, M.C., 2001. Constraint satisfaction in language acquisi- 1311 tion and processing. In: Christiansen, M.H., Charter, N. (Eds.), Connectionist 1312 Psycholinguistics. Ablex, Westport, CT, pp. 281-318. 1313

Seidenberg, M.S., Tanenhaus, M.K., Leiman, J.M., Bienkowski, M., 1982. Automatic access 1314 of the meanings of ambiguous words in context: some limitations of knowledge- 1315 based processing. Cogn. Psychol. 14, 489-537. 1316

Simmonds, D.J., Pekar, J.J., Mostofsky, S.H., 2008. Meta-analysis of Go/No-go tasks demon- 1317 strating that fMRI activation associated with response inhibition is task-dependent. 1318 Neuropsychologia $46 . \quad 1319$

Simpson, G.B., 1994. Context and the processing of ambiguous words. In: Gernsbacher, 1320 M.A. (Ed.), Handbook of Psycholinguistics. Academic Press, San Diego, CA, US, 1321 pp. 359-374. 1322

Smith, N.J., Levy, R., 2013. The effect of word predictability on reading time is logarithmic. 1323 Cognition 128, 302-319. 1324

Sörös, P., Guttman Sokoloff, L., Bose, A., McIntosh, A.R., Graham, S.G., Stuss, D.T., 2006. 1325 Clustered functional MRI of overt speech production. Neuroimage 32, 376-387. 1326

Spalek, K., Thompson-Schill, S.L., 2008. Task-dependent semantic interference in language 1327 production: an fMRI study. Brain Lang. 107, 220-228. 1328

Swallow, M.K., Braver, T.S., Snyder, A.Z., Speer, N.K., Zacks, J.M., 2003. Reliability of func- 1329 tional localization using fMRI. Neuroimage 20, 1561-1577. 1330

Swinney, D.A., 1979. Lexical access during sentence comprehension: (Re) consideration of 1331 context effects. J. Verbal Learn. Verbal Behav. 18, 523-534. 1332

Tanenhaus, M.K., Trueswell, J.C., 1995. Sentence comprehension. In: Miller, J., Eimas, P. (Eds.), 1333 Speech, Language and Communication. Academic Press, San Diego, CA, pp. 217-262. 1334

Tanenhaus, M.K., Leiman, J.M., Seidenberg, M.S., 1979. Evidence for multiple stages in the 1335 processing of ambiguous words in syntactic contexts. J. Verbal Learn. Verbal Behav. 1336 $18,427-440$

1337

Thompson-Schill, S.L., D'Esposito, M., Aguirre, G.K., Farah, M.J., 1997. Role of left inferior 1338 prefrontal cortex in retrieval of semantic knowledge: a reevaluation. Proc. Natl. 1339 Acad. Sci. U. S. A. 94, 14792-14797.

Thompson-Schill, S.L., Jonides, J., Marshuetz, C., Smith, E.E., D'Esposito, M., Kan, I.P., Knight, 1341 R.T., Swick, D., 2002. Effects of frontal lobe damage on interference effects in working 1342 memory. Cogn. Affect. Behav. Neurosci. 2, 109-120. 1343

Thompson-Schill, S.L., Bedny, M., Goldberg, R.F., 2005. The frontal lobes and the regulation 1344 of mental activity. Curr. Opin. Neurobiol. 15, 219-224. 1345

Thothathiri, M., Schwartz, M.F., Thompson-Schill, S.L., 2010. Selection for position: the 1346 role of left ventrolateral prefrontal cortex in sequencing language. Brain Lang. 113, 1347 28-38.

Traxler, M.J., Morris, R.K., Seely, R.E., 2002. Processing subject and object relative clauses: 1349 evidence from eye movements. J. Mem. Lang. 47, 69-90. 1350

Traxler, M.J., Williams, R.S., Blozis, S.A., Morris, R.K., 2005. Working memory, animacy, and 1351 verb class in the processing of relative clauses. Journal of Memory and Language 53, 1352 204-224.

Tremblay, P., Small, S.L., 2011. Motor response selection in overt sentence production: a 1354 functional MRI study. Frontiers in Psychology 2, 253. 1355

Trueswell, J.C., Tanenhaus, M.K., Garnsey, S.M., 1994. Semantic influences on parsing: use 1356 of thematic role information in syntactic ambiguity resolution. Journal of Memory 1357 and Language 33, 285-318.

Turkeltaub, P.E., Guinevere, F.E., Jones, K.M., Zeffiro, T.A., 2002. Meta-analysis of the func- 1359 tional neuroanatomy of single-word reading: method and validation. Neuroimage 16, 1360 765-780.

Tyler, L.K., Marslen-Wilson, W., 2008. Fronto-temporal brain systems supporting spoken 1362 language comprehension. Philos. Trans. R. Soc. Lond. B Biol. Sci. 363, 1037-1054. 1363

Wagner, A.D., Paré-Blagoev, E.J., Clark, J., Poldrack, R.A., 2001. Recovering meaning: left 1364 prefrontal cortex guides controlled semantic retrieval. Neuron 31, 329-338. 1365

Wahl, M., Marzinzik, F., Friederici, A.D., Hahne, A., Kupsch, A., Schneider, G.-H., Saddy, D., 1366 Curio, G., Klostermann, F., 2008. The human thalamus processes syntactic and seman- 1367 tic language violations. Neuron 59, 695-707. 1368

Whitney, C., Weis, S., Krings, T., Huber, W., Grossman, M., Kircher, T., 2008. Task- 1369 dependent modulations of prefrontal and hippocampal activity during intrinsic 1370 word production. J. Cogn. Neurosci. 21, 697-712. 1371

Whitney, C., Kirk, M., O'Sullivan, J., Lambon Ralph, M.A., Jefferies, E., 2011. The neural or- 1372 ganization of semantic control: TMS evidence for a distributed network in left inferior 1373 frontal and posterior middle temporal gyrus. Cereb. Cortex 21, 1066-1075. 1374

Wilson, S.M., Isenberg, A.L., Hickok, G., 2009. Neural correlates of word production stages 1375 delineated by parametric modulation of psycholinguistic variables. Hum. Brain Mapp. 1376 30, 3596-3608

1377

Wilson, S.D., Galantucci, S., Tartaglia, M.C., Rising, K., Patterson, D.K., Henry, M.L., Organ, 1378 J.M., DeLeon, J., Miller, B.L., Gorno-Tempini, M.L., 2011. Syntactic processing depends 1379 on dorsal language tracks. Neuron 72, 397-403.

Wise, R.J., Greene, J., Buchel, C., Scott, S.K., 1999. Brain regions involved in articulation. 1381 Lancet 353, 1057-1061.

Woolrich, M.W., Ripley, B.D., Brady, J.M., Smith, S.M.T., 2001. Temporal autocorrelation in 1383 univariate linear modelling of FMRI data. Neuroimage 14, 1370-1386. 1384 